Universidade de São Paulo

Faculdade de Medicina de Ribeirão Preto

\title{
2017
}

\section{Overreaching não funcional em modelo animal: adaptações inflamatórias e hipertróficas do músculo cardíaco.}
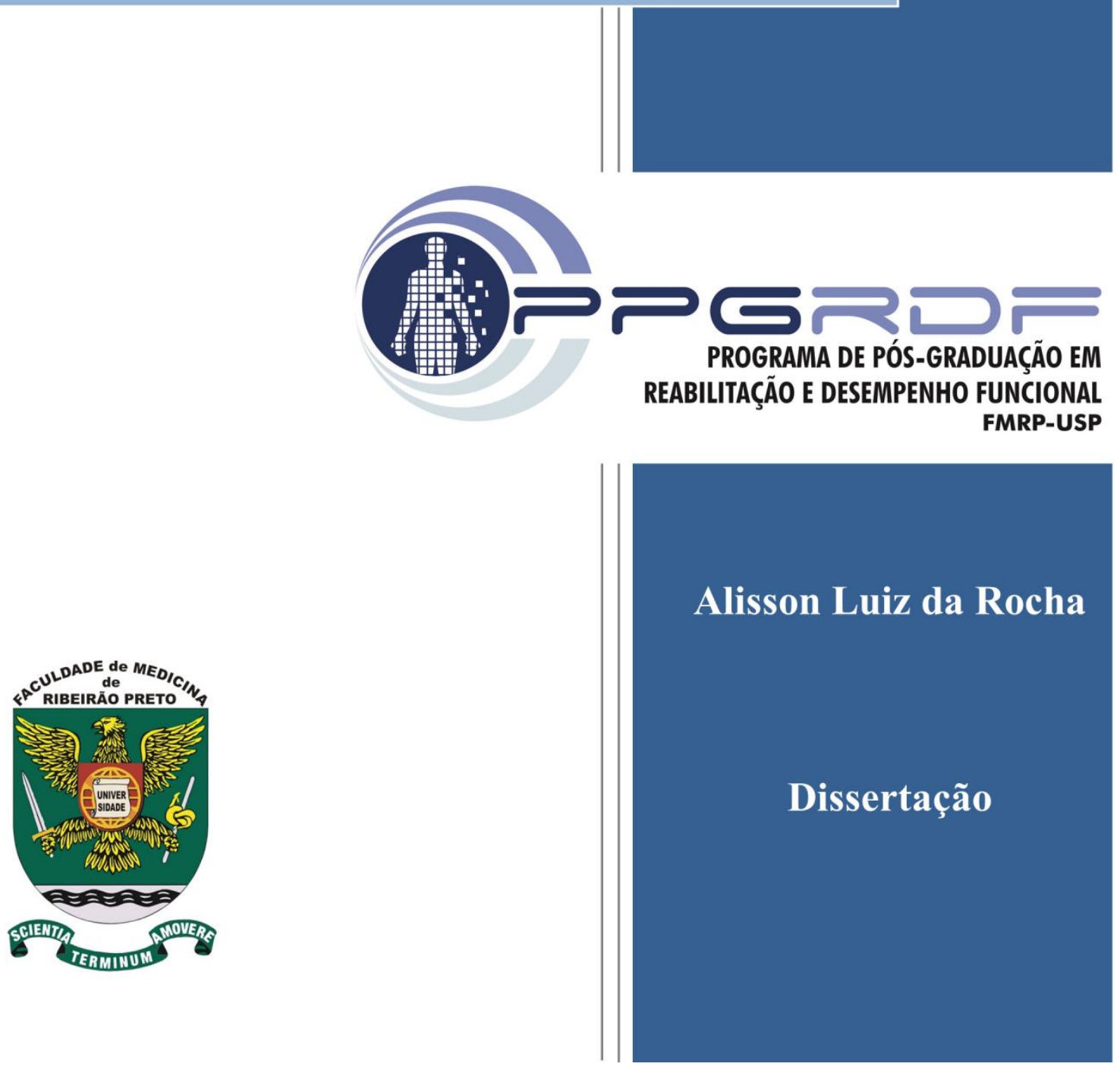
ALISSON LUIZ DA ROCHA

\section{OVERREACHING NÃO FUNCIONAL EM MODELO ANIMAL: ADAPTAÇÕES} INFLAMATÓRIAS E HIPERTRÓFICAS DO MÚSCULO CARDÍACO.

Dissertação de Mestrado apresentada à Faculdade de Medicina de Ribeirão Preto como requisito parcial para obtenção do título de Mestre em Ciências da Saúde do Programa de Pós-Graduação em Reabilitação e Desempenho Funcional da Universidade de São Paulo.

Orientador: Prof. Dr. Adelino Sanchez Ramos da Silva

Versão corrigida. A versão original encontra-se disponível tanto na Biblioteca da Unidade que aloja o Programa, quanto na Biblioteca Digital de Teses e Dissertação da USP (BDTD).

Ribeirão Preto 
Autorizo a reprodução e divulgação total ou parcial deste trabalho, por qualquer meio convencional ou eletrônico, para fins de estudo e pesquisa, desde que citada a fonte.

da Rocha, Alisson Luiz

Overreaching não funcional em modelo animal: adaptações inflamatórias e hipertróficas do músculo cardíaco, 2017.

54 p. : il. ; $30 \mathrm{~cm}$

Dissertação de Mestrado, apresentada à Faculdade de Medicina de Ribeirão Preto/USP. Área de concentração: Reabilitação e Desempenho Funcional.

Orientador: Da Silva, Adelino Sanchez Ramos. 
Nome: DA ROCHA, Alisson Luiz

Título: Overreaching não funcional em modelo animal: adaptações inflamatórias e hipertróficas do músculo cardíaco

Dissertação apresentada à Faculdade de Medicina de Ribeirão Preto da Universidade de São Paulo como requisito para título de Mestre no Programa de Pós Graduação em Reabilitação e Desempenho Funcional.

Aprovado em:

Banca Examinadora

Prof. Dr. Instituição:

Julgamento: Assinatura:

Prof. Dr. Instituição:

Julgamento: Assinatura:

Prof. Dr. Instituição:

Julgamento: Assinatura: 


\section{AGRADECIMENTOS}

A gratidão é muito importante em nossas vidas para nos mostrar que nada é realizado sozinho, e que nenhuma conquista tem significado se não refletir para alguém também.

Gostaria de agradecer primeiramente a Deus por todas as experiências e aprendizados que me proporcionou durante todo esse período, evoluí muito. Em sequência queria agradecer a minha família (pai, mãe e irmã) que me deram todo o suporte possível e inimaginável durante todos os anos da minha vida, através de amor, conselhos, paciência e sabedoria. Nada disso seria possível sem vocês, tudo isso é fruto do vosso amor. Agradeço também a minha noiva, Beatriz Tiburcio Silva Brosco, se mostrando presente em todos os momentos, desde os mais difíceis até os mais espetaculares. Foi de extrema importância sua contribuição em diversos sentidos, que vão desde intelectuais até motivacionais e afetivos. Sua presença em minha vida trouxe a serenidade que todo homem necessita para alcançar seus sonhos.

Agradeço ao meu orientador, Adelino Sanchez Ramos da Silva, que além da função de orientador, por muitas vezes se colocou na posição de amigo com conselhos não só profissionais, mas também na vida como um todo. Obrigado por sua confiança no meu trabalho e por acreditar em mim. Agradeço também aos meus companheiros de laboratório, que na verdade se tornaram grandes amigos, dentro e fora do ambiente de trabalho. Vocês foram sensacionais, cada ajuda e contribuição foi fundamental para que esse trabalho se concretizasse. Muito obrigado aos meus amigos, em especial a Eike Bianchi Kohama e Henrique Sanches Panobianco, que estão junto comigo nessa trajetória há mais de 6 anos, desde o início da graduação. Essa dissertação é a somatória de diversos fatores em minha vida, e com certeza vocês tiveram participação fundamental.

Agradeço a professora Giovana Rampazo Teixeira e a Lilian Eslaine Costa Mendes da Silva, que foram parceiras na realização dessa dissertação, contribuindo com a realização de análises e discussão enriquecedoras para a confecção deste trabalho.

Agradeço a todas a pessoas que de alguma forma ajudaram e contribuíram para a realização dessa fase em minha vida. Existem muitos nomes, mas com certeza quem partipou sabe de sua importância.

Agradeço a FAPESP pelo seu suporte financeiro. (2014/25459-9) 
"Mantenha seus pensamentos positivos, porque seus pensamentos tornam-se suas palavras. Mantenha suas palavras positivas, porque suas palavras tornam-se suas atitudes. Mantenha suas atitudes positivas, porque suas atitudes tornam-se seus hábitos. Mantenha seus hábitos positivos, porque seus hábitos tornam-se seus valores. Mantenha seus valores positivos, porque seus valores... Tornam-se seu destino" (Mahatma Gandhi) 


\section{RESUMO}

DA ROCHA, AL. Overreaching não funcional em modelo animal: adaptações inflamatórias e hipertróficas do músculo cardíaco. 2017, 54f Dissertação (Mestrado) Faculdade de Medicina de Ribeirão Preto, Universidade de São Paulo, Ribeirão Preto, 2017.

O overreaching não funcional (NFOR) induzido pelo exercício excêntrico (EE) em modelo animal está associado com a diminuição de desempenho físico, dano no DNA (amostras de músculo esquelético e soro), estresse oxidativo (amostras de músculo esquelético e soro), inflamação crônica de baixo grau (amostras de músculo esquelético e soro) e prejuízo da via de sinalização da insulina (amostras de músculo esquelético). No entanto, as adaptações do músculo cardíaco em resposta ao estado de NFOR induzido ou não pela predominância do EE ainda não foram investigadas. Além disso, sabe-se que a mTOR (mammalian target of rapamycin) possui um efeito protetor no músculo cardíaco, suprimindo o aumento de citocinas pró-inflamatórias, que estão relacionadas à disfunções cardíacas. Assim, o presente estudo teve como objetivo comparar os efeitos do NFOR em declive com outros dois protocolos de mesmo volume e intensidade, mas realizados sem inclinação e em aclive, no conteúdo das proteínas relacionadas às vias moleculares inflamatória e hipertrófica, no conteúdo de fibrose intersticial e na expresão gênica em músculo cardíaco de camundongos. Os animais foram divididos em 6 grupos: Naíve ( $\mathrm{N}$; camundongos sedentários), Controle ( $\mathrm{C}$; camundongos sedentários submetidos aos testes físicos), Treinado (TR; camundongos submetidos ao protocolo de treinamento), Overtraining em declive (OTR/down; camundongos submetidos ao protocolo de OT com corrida na descida), Overtraining sem inclinação (OTR; camundongos submetidos ao protocolo de OT com corrida sem inclinação) e Overtraining em aclive (OTR/up; camundongos submetidos ao protocolo de OT com corrida na subida). Em relação aos parâmetros metabólicos, o grupo OTR/down apresentou menor variação de peso corporal na semana 8. Todos os grupos que passaram pelo protocolo de OT demonstraram queda de desempenho ao final da semana 8, aumento no conteúdo de tecido conjuntivo no ventrículo esquerdo e menor ativação da proteína AMPKalfa. O grupo OTR/down apresentou menor conteúdo da proteína mTOR e S6RP, e aumento na expressão do gene beta-MHC. Pode-se concluir que os protocolos de OT provocaram indícios de hipertrofia patológica no ventrículo esquerdo, sendo esse efeito mais pronunciado no grupo OTR/down.

Palavras-chave: overtraining, hipertrofia, mTOR, coração, citocinas 


\begin{abstract}
da Rocha, AL. Nonfunctional overreaching in anima model: inflammatory and hypertrophic adaptations in cardiac muscle. Dissertação (Mestrado) - Faculdade de Medicina de Ribeirão Preto, Universidade de São Paulo, Ribeirão Preto, 2016.

Nonfunctional overreaching (NFOR) induced by eccentric exercise (EE) in animal model is associated with performance decrement, DNA damage (muscle and serum samples), oxidative stress (muscle and serum samples), low grade chronic inflammation (muscle and serum samples) and insulin signaling impairment (muscle and serum samples). However, the adaptations of cardiac muscle in response to NFOR induced or not induced by EE are unknown. In addition, the mammalian target of rapamycin (mTOR) has a protector effect in the cardiac muscle, suppressing the increase of the proinflammatory cytokines that is related to cardiac dysfunctions. Thus, the main aim of present study was to compare the effects of NFOR based on EE (downhill running) with other two protocols with similar intensity and volume, but performed in uphill and without inclination, on the protein contents related to hypertrophic and inflammatory signaling, on the content of interstitial fibrotic tissue and on genes expression in mice cardiac muscle. The animals were divided on six groups: Naïve (N; sedentary mice), Control (C; sedentary mice submitted to physical tests), Trained (TR; mice submitted to training protocol), Overtraining in downhill (OTR/down; mice submitted to the overtraining protocol in downhill), Overtraining without inclination (OTR; mice submitted to the overtraining protocol without inclination), and Overtraining in uphill (OTR/up; mice submitted to the overtraining protocol in uphill). Regarding metabolic parameters, OTR/down group presented reduced body weight variation at week 8 . All OT groups presented performance drop at end of week 8, increased connective tissue content in left ventricle and reduced AMPKalpha activation. OTR/down group presented reduced mTOR and S6RP protein content, and increased betaMHC gene expression. The conclusion is that OT protocols provoked signs of pathological hypertrophy in left ventricle, being this effect more pronounced in OTR/down group.
\end{abstract}

Keywords: overtraining, hypertrophy, mTOR, heart, cytokines 


\section{LISTA DE TABELAS}

Tabela 1. Resumo das principais características da hipertrofia fisiológica e patológica no músculo cardíaco 24

Tabela 2. Protocolo de treinamento 27

Tabela 3. Protocolo de overtraining em declive 27

Tabela 3. Protocolo de overtraining em aclive 28

Tabela 3. Protocolo de overtraining sem inclinação 28 


\section{LISTA DE FIGURAS}

Figura 1. Parâmetros metabólicos. A) Variação do peso corporal; B) Ingestão alimentar _... 32 Figura 2. Desempenho nos testes físicos. A) teste de carga incremental; B) teste exaustivo; C) teste de força de preensão; D) teste de rotarod

Figura 3. (A) Razão entre o peso do ventrículo esquerdo e o peso total do coração; (B) Atividade da enzima CK-MB no soro.

Figura 4. Níveis protéicos de (A) IL-1beta precursora, (B) IL-1beta madura, (C) IL-6, (D) TNFalfa precurora e (E) TNF-alfa madura no ventrículo esquerdo 35

Figure 5. Níveis protéicos de (A) p-Akt/Akt, (B) p-mTOR/mTOR, (C) p-p70S6K/p70S6K, (D) p-S6RP/S6RP, (E) p-4E-BP1/4E-BP1 e (F) p-AMPKalfa/AMPKalfa no ventrículo esquerdo 36

Figura 6. Níveis protéicos de (A) mTOR total e (B) S6RP total no ventrículo esquerdo.... 37

Figura 7. Análise histológica do ventrículo esquerdo. (A-F) Fotos representativas do tecido cardíaco marcado com o corante Masson's trichrome por análise histológica; (G) Conteúdo de tecido conjuntivo no ventrículo esquerdo.

Figura 8. Expressão gênica de (A) Atrial natriuretic factor, (B) Beta-myosin heavy chain e (C) Skeletal muscle actin no ventrículo esquerdo. 38 


\section{LISTA DE ABREVIATURAS}

4E-BP1 - 4E binding protein

Akt - protein kinase $B$

AMPK - AMP-activated protein kinase

$\mathrm{ANF}$ - atrial natriuretic factor

CK-MB - creatina quinase isoenzima MB

CT - Controle

EE - exercício excêntrico

EIF-4E - eukaryotic translation initiation factor $4 E$

FOR - overreacing funcional

GPCR - G protein-coupled receptors

HSF1 - heat shock transcription factor

IAM - infarto agudo do miocárdio

IGF-1 - insulin growth factor 1

IL-1beta - interleucina 1 beta

IL-6 - interleucina 6

JAK - janus kinase

MAPK - membro da família das proteínas quinases ativadas por mitógeno

$\mathrm{MHC}$ - myosin heavy chain

mTOR - mammalian target of rapamicin

$\mathrm{N}$ - Naíve

NF-kB - nuclear factor kappa $B$

NFOR - overreaching não funcional

OR - overreaching

OT - overtraining

OTR - Overtraining sem inclinação

OTR/down - Overtraining em declive

OTR/up - Overtraining em aclive

OTS - síndrome do overtraining

PI3K - phosphoinositide 3 kinase

$\mathrm{PKC}$ - protein kinase $C$

S6K - ribosomal S6 kinase

S6RP - ribosomal protein S6 
SAPK/JNK - stress-activated protein kinases/Jun amino-terminal kinases

Sk. Actin - skeletal actin

SOCS-3 - supressor de sinalização de citocina 3

STAT - signal transducer and activators of transcription

TLR4 - toll like repector 4

TNF-alfa - fator de necrose tumoral alfa

TR - Treinado 


\section{SUMÁRIO}

1. INTRODUÇÃ

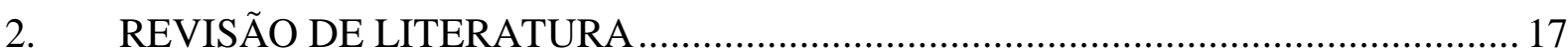

2.1 Overreaching funcional, overreaching não funcional e síndrome do overtraining .... 17

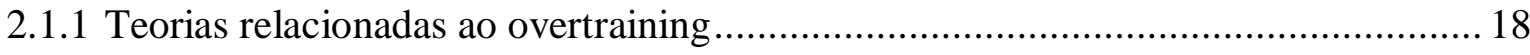

2.1.2 Avanços no estudo do overtraining em modelo animal .......................................... 19

2.2 Adaptações moleculares do tecido cardíaco ........................................................... 22

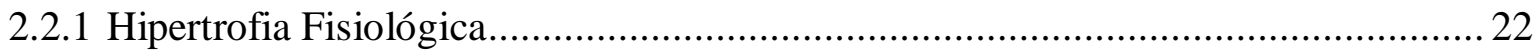

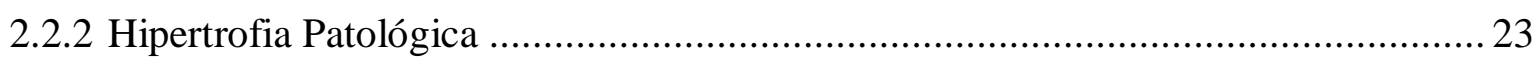

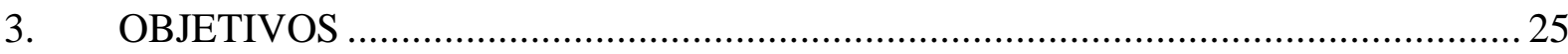

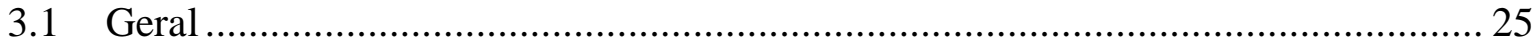

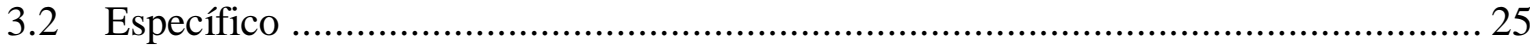

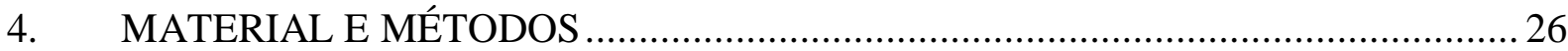

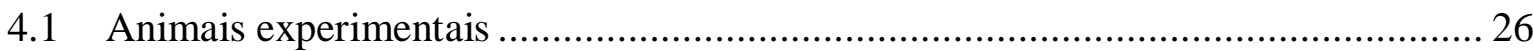

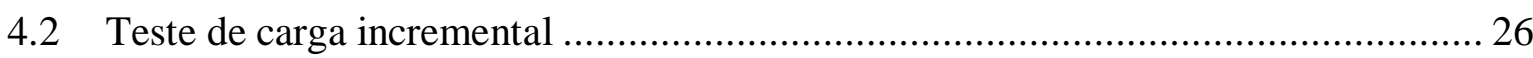

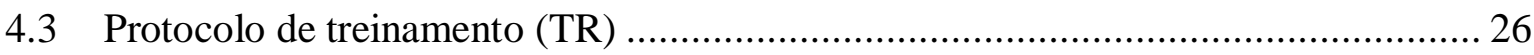

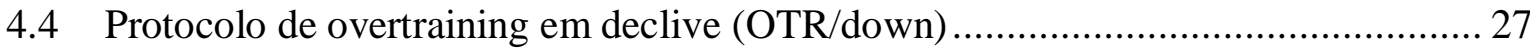

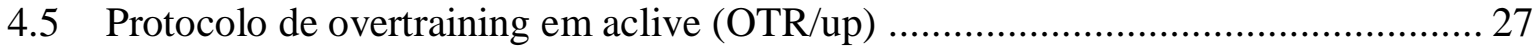

4.6 Protocolo de overtraining sem inclinação (OTR) .................................................. 28

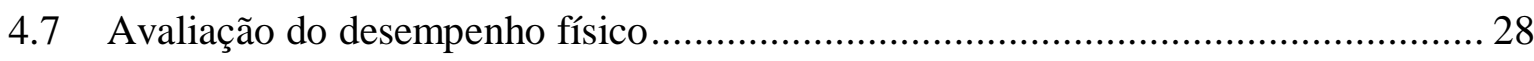

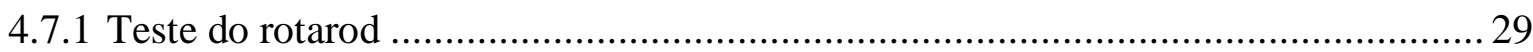

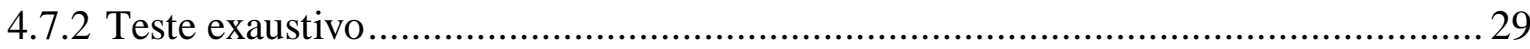

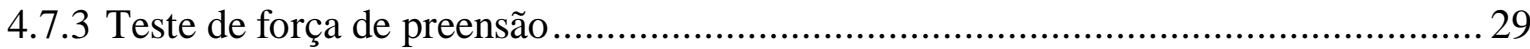

4.8 Avaliação de parâmetros metabólicos .......................................................................... 29

4.9 Extração do músculo cardíaco e sangue ...................................................................... 29

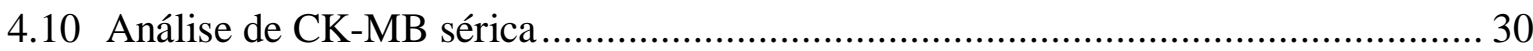

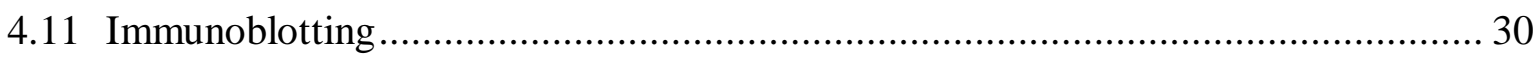

4.12 Avaliação da fibrose intersticial no miocárdio ...................................................... 31

4.13 Real Time - Polymerase Chain Reverse (PCR) .................................................. 31

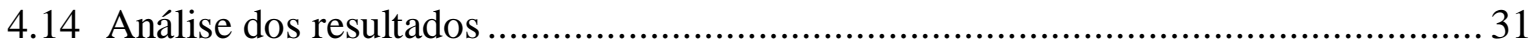

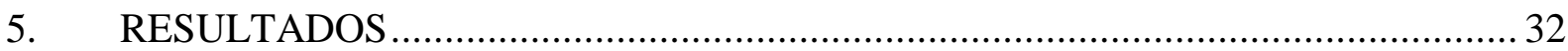

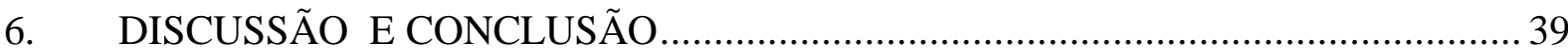


7. ATIVIDADES REALIZADAS 44

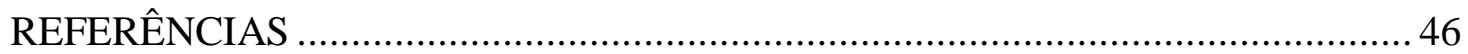




\section{INTRODUÇÃO}

No esporte de alto nível, os principais objetivos de um programa de treinamento são a maximização e a manutenção do desempenho esportivo do atleta ao longo de uma temporada competitiva (Armstrong e Vanheest, 2002). Para que isso ocorra, sessões de treino de alta intensidade são comumente utilizadas durante programas de treinamento em diversas modalidades esportivas. Ao atingir os objetivos propostos pelo programa de treinamento, a maximização do desempenho esportivo ocorre como resultado de adaptações fisiológicas em diversos sistemas do corpo humano, inclusive no sistema cardiovascular que apresenta maior capacidade de transporte dos nutrientes e substratos necessários para o funcionamento do metabolismo (Huonker et al., 1996).

No entanto, em busca das adaptações fisiológicas positivas durante um programa de treinamento, a utilização de treinos de alta intensidade podem acarretar momentaneamente na diminuição de desempenho e aparecimento da fadiga aguda. Nesse momento, é importante que a comissão técnica propicie ao atleta um período adequado de recuperação, para que o mesmo possa ser beneficiado pela supercompensação e, consequentemente, pela melhora do desempenho físico. Contudo, caso essa queda momentânea de desempenho seja combatida com mais treinamento, o atleta pode apresentar um desequilíbrio entre a demanda do exercício e o período destinado à sua recuperação, o que pode ocasionar no aparecimento do overreaching (OR) (Halson e Jeukendrup, 2004).

De acordo com Kreider e colaboradores (Kreider et al., 1998), o OR pode ser definido como um acúmulo de estresse proveniente do treinamento e/ou de situações extratreinamento que resulta na diminuição do desempenho esportivo durante um curto período de tempo, podendo ou não estar associado a sintomas fisiológicos e psicológicos. A recuperação de um atleta em OR ocorre após a diminuição ou interrupção total das cargas de treino durante aproximadamente duas semanas. Caso o atleta não seja submetido ao período de recuperação destacado acima, o mesmo corre o risco de desenvolver o overtraining (OT), que também pode ser definido como um acúmulo de estresse proveniente do treinamento e/ou de situações extratreinamento. O OT está relacionado com a diminuição do desempenho esportivo durante um longo período de tempo e pode ou não estar associado a sintomas fisiológicos e psicológicos. A recuperação de um atleta em OT ocorre após a diminuição ou interrupção total das cargas de treino durante semanas ou meses. 
No presente trabalho, adotaremos os seguintes termos propostos por Meeusen e colaboradores (Meeusen et al., 2006): overreaching funcional (FOR), caracterizado por uma queda de desempenho que não está relacionada com outros aspectos psicológicos e/ou fisiológicos negativos e pode ser revertida após alguns dias de recuperação; overreaching não funcional (NFOR), caracterizado por uma queda de desempenho que pode ser revertida após semanas ou meses de recuperação, e está associada com distúrbios psicológicos (aumento da fadiga e diminuição do vigor) e hormonais; e síndrome do overtraining (OTS), caracterizada por uma queda de desempenho que pode perdurar meses ou anos, e em que os atletas frequentemente apresentam os mesmos sinais e sintomas observados no NFOR. Portanto, o diagnóstico da OTS exige a presença de um estado prolongado de mal adaptação não apenas do desempenho do atleta, mas também de mecanismos regulatórios dos sistemas biológicos, neuroquímicos e hormonais.

Os avanços nas áreas de estudos de FOR, NFOR e OTS são prejudicados devido à variabilidade dos desenhos experimentais e à falta de atletas dispostos a arriscarem uma temporada de treinamento e suas respectivas competições para contribuir com as pesquisas nessa área (Armstrong e Vanheest, 2002; Halson e Jeukendrup, 2004). Nesse sentido, a Sociedade Americana de Fisiologia incentiva a utilização de modelos animais quando não é apropriado estudar os efeitos do exercício físico nos seres humanos (Society, 2006). Recentemente, Pereira e colaboradores (Pereira et al., 2012) desenvolveram um protocolo de OT baseado em sessões crônicas de corrida em declive que induziu o NFOR em camundongos. Posteriormente, com o intuito de investigar as relações entre a queda de desempenho induzida por sessões crônicas de exercício excêntrico (EE) e as hipóteses que consideram o papel central das citocinas na etiologia da OTS (Smith, 2000; Robson, 2003), Pereira e colaboradores (Pereira et al., 2014a) verificaram que camundongos em NFOR apresentaram inflamação crônica de baixa intensidade tanto em músculos esqueléticos (altas concentrações protéicas de interleucina 6 - IL-6, e do fator de necrose tumoral alfa - TNF-alfa) quanto em soro (altas concentrações de IL-6), além de altas concentrações protéicas de miostatina em amostras de músculo esquelético.

Da mesma forma que o músculo esquelético, o miocárdio também tem a capacidade de produzir citocinas pró-inflamatórias como a interleucina 1-beta (IL-1beta), IL-6 e TNF-alfa (Herskowitz et al., 1995; Steensberg et al., 2002). Song e colaboradores (Song et al., 2010) verificaram que altos níveis de citocinas pró-inflamatórias, incluindo as supracitadas, estão aumentadas durante o estado de insuficiência cardíca, e que a via de sinalização da mTOR (mammalian target of rapamycin) tem um efeito cardioprotetor, suprimindo o aumento de IL6 e IL-1beta através da redução da ativação do NF-KB (nuclear factor- $k B$ ), um importante fator 
de transcrição mediado pela via de sinalização do TLR4 (toll like receptor 4) presente em células imunes (Medzhitov e Janeway, 1997) e cardíacas (Frantz et al., 1999).

Durante um programa de treinamento aeróbio, o músculo cardíaco apresenta adaptações ao estresse fisiológico, como o aumento da massa e da contratilidade do miocárdio (Ferguson et al., 2001). A hipertrofia fisiológica contribui para aumentar a capacidade de bombeamento do coração e maximiza o transporte de sangue e oxigênio para o músculo esquelético, fazendo com que ocorra aumento da capacidade de realizar exercícios físicos (melhora do desempenho físico) (Richardson, 1998). Vários estudos utilizando modelo animal demonstraram que a hipertrofia fisiológica do miocárdio induzida através de exercícios físicos adequados é acompanhada pela ativação das proteínas relacionadas à via de sinalização da mTOR (IGF-1 insulin like growth factor 1 - PI3K - phosphoinositide 3-kinase - AKT - Protein kinase B mTOR) (Wisløff et al., 2001; Wisløff et al., 2002; Kemi et al., 2004; Kemi et al., 2005; Kemi et al., 2006).

De acordo com Kemi e colaboradores (Kemi et al., 2008), o treinamento aeróbio intervalado de alta intensidade também ativa a via de sinalização da AKT/mTOR e seus substratos (S6K - ribossomal S6 kinase, S6RP - S6 ribossomal protein, 4EBP1 - 4E binding protein). Na realidade, a ativação da cascata de sinalização da AKT/mTOR sugere que a síntese protéica no coração é aumentada em decorrência de um programa de treinamento físico, isso significa que existe um aumento na fosforilação da proteina S6RP (S6 ribossomal protein) e na liberação do eIF-4E (eukaryotic translation initiation factor $4 E$ ). Assim, ocorre aumento da atividade dos ribossomos, juntamente com a taxa de síntese protéica nos cardiomiócitos (Walsh, 2006). A hipertrofia do músculo cardíaco difere de acordo com o estresse exercido no miocárdio. Por exemplo, se o estímulo for proveniente de quadros patológicos como a hipertensão arterial, a hipertrofia do miocárdio ocorre por outra via de sinalização em que genes fetais específicos (ANF - atrial natriuretic factor, MHC - beta-myosin heavy chain e Sk. Actin - skeletal muscle actin) são reativados, aumentando o acúmulo de fibrose intersticial no tecido cardíaco e diminuindo a ativação das proteínas relacionadas à via de sinalização da mTOR, o que em última instância provoca diminuição na capacidade de contração muscular cardíaca e prejuízo no desempenho físico (Molkentin e Dorn Ii, 2001; Mcmullen et al., 2003; Kemi et al., 2008).

Com relação às investigações acerca do NFOR em modelo animal, até o presente momento, nossos estudos demonstraram que a associação entre sessões crônicas de EE e períodos limitados de recuperação está diretamente relacionada com a diminuição de desempenho físico, dano no DNA (amostras de músculo esquelético e soro), estresse oxidativo 
(amostras de músculo esquelético e soro), inflamação crônica de baixo grau (amostras de músculo esquelético e soro) e prejuízo da via de sinalização da insulina (amostras de músculo esquelético) (Pereira et al., 2012; Pereira et al., 2013; Pereira, B. et al., 2014; Pereira, B. C. et $a l ., 2014)$. Além disso, já foi descrito na literatura que o dano muscular provocado pelo EE é responsável pelas altas concentrações séricas de TNF-alfa (Del Aguila et al., 2000). Dessa maneira, é possível afirmar que os nossos resultados (Pereira et al., 2014a) corroboram a literatura específica acerca da relação entre EE e inflamação (Del Aguila et al., 1999). No entanto, o efeito do aumento das citocinas pró-inflamatórias em resposta ao EE agudo (Davis et al., 2007) e crônico na via de sinalização da mTOR no tecido cardíaco é desconhecido.

Além disso, sabe-se que o EE possui características singulares, como o alongamento do complexo músculo-tendão (Lindstedt et al., 2001), estratégias únicas de recrutamento pelo sistema nervoso (Enoka, 1996), além de alta produção de força com baixa exigência de oxigênio (Abbott e Bigland, 1952). O estresse mecânico imposto pelo EE também pode ser responsável pelas adaptações específicas desse tipo de contração (S et al., 2013). Portanto, embora o NFOR possa ser induzido em roedores utilizando o exercício físico em esteira rolante sem a predominância do EE (Da Rocha et al., 2015; Pereira, B. et al., 2015; Pereira, B. C. et al., 2015), até o presente momento, não é possível afirmar que o NFOR induzido através da corrida em esteira rolante em aclive ou sem inclinação também está associado com o aumento das concentrações de citocinas pró-infamatórias.

De qualquer maneira, as adaptações do músculo cardíaco em resposta ao estado de NFOR induzido ou não pela predominância do EE ainda não foram investigadas. Mesmo diante da diminuição de desempenho induzida pelos diferentes modelos de OT propostos pelo nosso grupo de pesquisa (Pereira et al., 2012; da Rocha et al., 2015; Pereira et al., 2015), é possível que a via da mTOR do tecido cardíaco dos roedores em NFOR seja ativada, promovendo hipertrofia fisiológica e efeito cardioprotetor em relação a produção de citocinas próinflamatórias (Song et al., 2010), que foram encontradas em altas concentrações nos roedores submetidos ao protocolo de OT baseado em sessões crônicas de EE (Pereira et al., 2014a). Por outro lado, é possível que o desequilíbrio entre o excesso de exercício físico e o período destinado para a recuperação dos roedores induza reativação dos genes fetais supracitados, acúmulo de fibrose intersticial no tecido cardíaco, diminuição da sinalização da via da mTOR e diminuição da capacidade de contração muscular cardíaca, contribuindo para a diminuição do desempenho físico observada previamente (da Rocha et al., 2015) 


\section{REVISÃO DE LITERATURA}

\subsection{Overreaching funcional, overreaching não funcional e síndrome do overtraining}

Sabe-se que o desequilíbrio entre o treinamento e o período de recuperação do atleta está associado com o desenvolvimento do overreaching (OR) e/ou overtraining (OT) (Kreider et al., 1998). Recentemente, devido à inexistência de uma terminologia comum e consistente sobre essas disfunções, renomados pesquisadores associados ao European College of Sport Science (ECSS) e ao ACSM publicaram um trabalho de revisão de literatura cujo objetivo foi fornecer um consenso mútuo dessas duas respeitadas organizações internacionais sobre definições, diagnósticos, tratamentos e prevenções no que tange a síndrome do overtraining (OTS) (Meeusen et al., 2013). Com base nesse trabalho previamente citado, utilizaremos as seguintes terminologias: overreaching funcional (FOR), overreaching não funcional (NFOR) e síndrome do overtraining (OTS). No FOR, também denominado de OR de curto prazo, o atleta é submetido a um período intensificado de treinamento que pode resultar em diminuição temporária de desempenho. Após um período adequado de recuperação, o atleta apresenta supercompensação, elevando os níveis de desempenho quando comparado a linha de base. "No FOR, as respostas fisiológicas irão compensar o estresse promovido pela intensificação do treinamento" (Steinacker et al., 2005)).

Quando a estratégia de intensificação de treinamento é mantida, o atleta pode evoluir para o NFOR, também denominado como OR extremo, que está associado com a estagnação ou queda de desempenho, que pode ser revertida após semanas ou meses de recuperação, e está associada com distúrbios psicológicos e hormonais. Por outro lado, a OTS é caracterizada por uma diminuição de desempenho que pode durar meses ou anos. Na realidade, devido à semelhança nas alterações clínicas e hormonais entre os estados de NFOR e OTS, o diagnóstico do último exige a exclusão de uma série de fatores, inclusive de patologias, que podem estar influenciando a diminuição do desempenho e as alterações de humor (Meeusen et al., 2013).

A noção da exata prevalência do NFOR/OTS é de difícil mensuração, devido ao banco de dados científicos utilizar diversas terminologias, diferentes delineamentos experimentais e ausência de dados relevantes, porém alguns estudos apontam estatísticas em certas situações e esportes. Morgan et al. (Morgan et al., 1988) demonstram que 64\% de corredores de elite do sexo masculino e $60 \%$ do sexo feminino exibiram pelo menos um episódio de OTS em sua carreira competitiva, sendo que em nível amador essa porcentagem é menor, ficando em torno de 33\%. Kentta et al. (Kenttä et al., 2001) evidenciaram que na Suécia, em nível de atletas 
juniores internacionais, 37\% apresentaram sintomas de NFOR/OTS em 16 diferentes esportes. Além do mais, atletas que tem um histórico de OTS em sua carreira possuem alto risco de nova ocorrência, chegando a 91\% de recaída como demonstrado no estudo de Raglin (Raglin, 1993), onde foram avaliados nadadores colegiais dos Estados Unidos.

Até o presente momento, o padrão ouro para detecção do NFOR/OTS é a queda de performance, porém existe uma lista dos principais sintomas indicados por sua prevalência na literatura (Fry et al., 1991):

- Performance Fisiológica: queda de performance; depleção de minerais; aumento na concentração de uréia; reduzida tolerância a carga de treino; recuperação prolongada; queda de força muscular; perda de coordenação; reaparição de erros previamente já corrigidos; anormalidades no comportamento da onda $\mathrm{T}$ no eletrocardiograma; mudanças na pressão sanguínea; mudanças na freqüência cardíaca de repouso, de treino e de recuperação; aumento na freqüência respiratória; perda de gordura corporal; fadiga crônica; sensação de sede; perda de apetite; dores de cabeça; distúrbios gastrointestinais; sensação de dor muscular; entre outros.

- Psicológicos/Processamento das informações: sentimento de depressão; apatia; instabilidade emocional; dificuldade de concentração no trabalho e treino; estresse emocional; medo da competição; mudanças na personalidade; dificuldade em lidar com grandes quantidades de informação; desistir de situações que se tornam desafiadoras; entre outros.

- Imunológicos: aumento na susceptibilidade a vários tipos de resfriados, alergias e gripes; cicatrização mais lenta; resfriados de um dia; queda da atividade de linfócitos funcionais; queda na contagem de linfócitos totais; aumento na contagem de enófilos no sangue; infecções bacterianas; reativação da infecção do vírus do herpes; variações significantes entre linfócitos CD4:CD8; entre outros.

- Bioquímicos: disfunção hipotalâmica; depleção da concentração de glicogênio muscular; queda no conteúdo mineral óssea; queda na concentração de hemoglobina; queda na concentração sérica de ferro; níveis elevados de cortisol; reduzida quantidade de testosterona; aumento na produção de ácido úrico; entre outros.

\subsubsection{Teorias relacionadas ao overtraining}

Para a explicação da OTS, existem várias teorias que foram propostas, algumas ainda continuam viáveis, mas outras já não possuem mais tanto suporte. Alguns pesquisadores, como Lehmann et al. (Lehmann et al., 1998) e Keizer (Keizer, 1998) focaram nos processos 
envolvidos no hipotálamo, que é o local a qual resulta na ativação do sistema nervoso autônomo, eixo hipotálamo-pituitária-adrenal e eixo hipotálamo-pituitária-gônadas, resultando em alterações das catecolaminas, glicocorticóides, e níveis de testosterona sanguíneo. Não há dúvidas que essas alterações estão relacionadas ao OTS, porém essas alterações podem ser conseqüências e não causas propriamente ditas.

Em seu estudo, Newsholme et al. (Newsholme et al., 1991) propuseram a teoria da glutamina, em que a reduzida concentração de glutamina sanguínea é responsável pela resposta imunológica frequentemente prejudicada durante a OTS, já que a própria glutamina é o combustível primário utilizado pelos linfócitos, células de defesa do nosso organismo. Já Costill et al. (Costill et al., 1988), propuseram a teoria do glicogênio, que sugere que certos atletas são incapazes de manter uma ingestão calórica suficiente em resposta a dramáticos aumentos nas cargas de treino. Esse desbalanço entre ingestão alimentar e gasto calórico, provocaria uma redução nos estoques de glicogênio nos músculos esqueléticos, resultando na sensação de fadiga e queda de performance, sintomas largamente evidenciados na literatura. Foster et al. (Foster et al., 1997), sugeriram a teoria da monotonia do treinamento, onde a monotonia psicológica, tem impactos na performance fisiológica, e a repetição sempre do mesmo treinamento pode impor um estresse excessivo no sistema músculo-tendão-articulação, fazendo com que o atleta esteja mais propenso a ter lesões.

Em sua teoria, Smith (Smith, 2000) concilia vários mecanismos propostos por outros pesquisadores previamente citados. A OTS como sendo resposta ao estresse no músculo esquelético excessivo, associado com descanso e recuperação insuficiente, induz a uma resposta inflamatória local, que está envolvido com uma inflamação crônica e procede a uma inflamação sistêmica. Parte dessa inflamação sistêmica envolve a ativação de monócitos circulantes (células imunitárias), os quais sintetizam uma grande quantidade de citocinas pró-inflamatórias, como a IL-1beta, IL-6, e TNF-alfa. As citocinas atuam no sistema nervoso central e induzem a modificações de comportamentos, comumente referidos como doença, já citados na literatura anteriormente. As citocinas também atuam no sistema nervoso simpático e eixo hipotálamopituitária-gonadal, modificando a concentração de catecolaminas, glicocorticóides e homônios gonadais no sangue, como também podem aumentar a atividade hepática para manutenção da glicose sanguínea.

\subsubsection{Avanços no estudo do overtraining em modelo animal}

Recentemente, Hohl et al. (Hohl et al., 2008) desenvolveram e caracterizaram um protocolo para indução do OT em ratos Wistar utilizando esteira ergométrica como modelo de 
exercício. Nesse estudo, os autores não verificaram diferenças nas concentrações de glicogênio muscular entre os animais treinados e aqueles em OR não funcional, ou seja, que não apresentaram melhora de desempenho após duas semanas de recuperação passiva ao final do protocolo de OT. No entanto, o intervalo de 60h entre a última sessão de exercício e o sacrifício dos animais pode ser considerado como o principal responsável pela falta de diferença significativa entre o conteúdo de glicogênio muscular de ambos os grupos.

O protocolo proposto por Hohl et al. (Hohl et al., 2008) foi extremamente importante para o avanço na área de conhecimento sobre OR e OT, visto que a utilização de roedores permitiu um maior controle no que se refere às cargas de treinamento e ingestão alimentar em comparação com investigações envolvendo seres humanos. Além disso, abrem possibilidades para estudar quais são os mecanismos moleculares que explicam a diminuição da performance como resultado do desequilíbrio entre o excesso de treinamento e o período de recuperação.

Nesse contexto, Pereira et al. (Pereira et al., 2012) desenvolveram um novo protocolo para a indução da OTS em camundongos baseado na corrida em declive que foi capaz de induzir o NFOR em 100\% dos animais que realizaram esse protocolo, apresentando queda de performance, um dos principais parâmetros utilizados para confirmar o NFOR. Posteriormente, com o intuito de investigar as relações entre a queda de desempenho induzida por sessões crônicas de exercício excêntrico (EE) e as hipóteses que consideram o papel central das citocinas na etiologia do OR e OT (Smith, 2000; Robson, 2003), Pereira et al. (Pereira et al., 2014a) verificaram que camundongos em NFOR apresentaram inflamação crônica de baixa intensidade tanto em músculos esqueléticos (altas concentrações protéicas de interleucina 6, IL6, e do fator de necrose tumoral alfa, TNF-alfa) quanto em soro (altas concentrações de IL-6), além de altas concentrações protéicas de miostatina em amostras de músculo esquelético.

Como os altos níveis de IL-6, TNF-alfa e miostatina estão diretamente relacionados com o prejuízo da via de sinalização da insulina (Hittel et al., 2010), Pereira et al. (Pereira et al., 2014b) investigaram os efeitos do protocolo de OT baseado em EE e aplicado em camundongos nos conteúdos protéicos e na fosforilação do substrato do receptor de insulina 1 (IRS1; pIRS1), do receptor de insulina beta (IRbeta; pIRbeta) e da proteína quinase B (Akt; pAkt) em músculos esqueléticos com diferentes predominância de fibras musculares. Além disso, outras proteínas como a IкB kinase (IKK), um complexo enzimático relacionado com a resposta celular inflamatória, a SAPK/JNK (the stress-activated protein kinases/Jun amino-terminal kinases), membro da família das proteínas quinases ativadas por mitógeno (MAPK), e o supressor de sinalização de citocina 3 (SOCS3), membro da família dos supressores de sinalização de citocina (SOCS), também estão relacionadas com o prejuízo da via de sinalização da insulina 
na musculatura esquelética (Jorgensen et al., 2013; Ropelle et al., 2013). Dessa forma, os autores constataram que o protocolo de OT baseado em EE prejudicou a transdução do sinal da via de sinalização da insulina com concomitante aumento dos níveis protéicos de IKK, SAPK/JNK e SOCS3.

Apesar do exercício excêntrico possuir singularidades, como o alongamento do complexo músculo-tendão (Lindstedt et al., 2001), estratégias únicas de recrutamento pelo sistema nervoso (Enoka, 1996) e alta produção de força com baixa exigência de oxigênio (Abbott e Bigland, 1952), Pereira et al. (Pereira et al., 2015a) demonstraram que o NFOR pode ser induzido através de exercício físico sem predominância de contrações excêntricas. Nesse estudo foram utilizados outros dois grupos que realizaram o protocolo de OT de mesmo volume e intensidade, porém um foi realizado com predominância de contrações concêntricas (corrida em aclive) e outro em corrida sem inclinação. Nos parâmetros dos testes físicos, todos os 3 grupos (corrida em declive, corrida em aclive e corrida sem inclinação) apresentaram queda de performance similares, demonstrando que o principal fator para indução do NFOR é o desequilirio entre sessões de treino e recuperação.

Afim de continuar investigando as adaptações moleculares em resposta ao NFOR no músculo esquelético, Pereira et al. (Pereira et al., 2016) verificaram que o protocolo de OT baseado em contrações excêntricas foi capaz de induzir estresse do retículo endoplasmático ligado a uma condição patológica, sugerindo uma relação com o estado inflamatório previamente encontrado nas amostras de músculo esquelético. Já em relação aos dados preliminares do conteúdo elevado de miostatina em músculo esquelético (Pereira, B. et al., 2014a), da Rocha et al. (da Rocha et al., 2016) investigaram as adaptações da via de sinalização da mTOR e as características morfológicas do tecido muscular (EDL e sóleo), demonstrando que o grupo que realizou o protocolo de OT em declive exibiu sinais de atrofia muscular.

Em 2015, Pereira e colaboradores (Pereira et al., 2015b) verificaram a existência de uma inflamação transitória no hipotálamo dos camundongos que realizaram o protocolo de OT em declive, sendo que logo após o término das sessões de OT foram encontrados altos níveis de citocinas pró-inflamatórias no tecido hipotalâmico, e após duas semanas de recuperação total esses níveis voltaram aos níveis basais. Essa inflamação hipotalâmica pode estar relacionada a menor ingestão alimentar observada nesse grupo durante a última semana do protocolo de OT. Da Rocha et al. (da Rocha et al., 2015) também verificaram algumas respostas moleculares do fígado aos protocolos de OT, demonstrando novamente que o grupo que realizou o protocolo em declive apresentou alterações, exibindo aumento na sensibilidade da via de sinalização da insulina sem aumento de citocinas pró-inflamatorias. 
Outros tecidos podem sofrer adaptações decorrentes do estresse imposto pelo treinamento excessivo, podendo ser fatores chaves para a explicação da queda de perfomance observada no estado de NFOR. O músculo cardíaco, através de diversos estímulos (fisiológicos e/ou patológicos), possui a capacidade de se adaptar ao estresse imposto, sendo que diferentes estímulos podem levar a uma mesma resposta adaptativa, porém essa resposta pode se mostrar benéfica ou maléfica, como a hipertrofia cadíaca.

\subsection{Adaptações moleculares do tecido cardíaco}

A hipertrofia cardíaca pode ser definida brevemente como o aumento da massa muscular cardíaca, sendo que esse aumento é expressivamente devido ao aumento do peso do ventrículo esquerdo (Bernardo et al., 2010).Ela pode ser classificada em dois tipos: hipertrofia fisiológica e hipertrofia patológica; sendo que depende do início de vários eventos em resposta ao estímulo específico, levando a ativação de vias de sinalizações moleculares específicas, mudança na expressão gênica, aumento na taxa de síntese protéica e organização das proteínas contráteis nos sarcômeros (Estigoy et al., 2009).

\subsubsection{Hipertrofia Fisiológica}

O aumento fisiológico do coração inclui o crescimento normal pós-natal, crescimento decorrente da gravidez e hipertrofia cardíaca induzida pelo exercício físico, sendo associado a uma estrutura cardíaca normal, aumento da função cardíaca e pode ser reversível nos casos de gravidez e treinamento físico (Fagard et al., 1997).

A especificidade do exercício físico pode levar a diferentes tipos de hipertrofia fisiológica. O exercício físico aeróbico, de longa duração e intensidade moderada, aumenta o retorno venoso para o coração e resulta em uma sobrecarga de volume sanguíneo levando a hipertrofia excêntrica, sendo classificada como aumento da cavidade ventricular proporcional a sua espessura. Nesse caso os sarcômeros são adicionados em série, aumentando o comprimento da fibra do músculo cardíaco. Já no caso do exercício físico resistido, ele resulta em aumento da pressão sanguínea no coração, acarretando a hipertrofia concêntrica, exibindo aumento na espessura da parede ventricular e massa muscular, com uma pequena redução ou nenhuma alteração no volume da cavidade cardíaca. Na hipertrofia concêntrica os sarcômeros são adicionados em paralelo, aumentando espessura da célula (Pluim et al., 2000).

Existem certas vias moleculares que demonstram estar relacionadas com a hipertrofia fisiológica do coração, como a via JAK (janus kinase)/STAT (signal transducer and activators of transcription), sinalização do hormônio da tireóide e o HSF1 (heat shock transcription factor 
1), que podem contribuir para todas as adaptações previamente citadas. Porém a cascata de sinalização PI3k-AKT-mTOR é a mais bem caracterizada na literatura, no sentindo de orquestrar todos os eventos moleculares que levam ao aumento da síntese protéica cardíaca, consequente hipertrofia, estando relacionada ao aumento da funcionalidade do coração (Wisløff et al., 2001; Wisløff et al., 2002; Kemi et al., 2004; Kemi et al., 2005; Kemi et al., 2006). A via de sinalização da mTOR é sensível a nutrientes e estímulos anabólicos (GH, IGF-1, insulina), sendo que através desses sinais extracelulares, a proteína AKT se torna ativa, sendo fosforilada no resíduo serina 473, e desencadeia a ativação de sua proteína alvo mTOR. A mTOR é uma proteína clássica relacionada a síntesa protéica, sendo responsável por ativar suas proteínas alvo: S6K, S6RP e 4EBP1, levando ao aumento na eficiência da tradução protéica nos ribossomos. (Bodine, 2006).

\subsubsection{Hipertrofia Patológica}

A hipertrofia patológica, como o próprio nome diz, é decorrente de quadros onde existe uma patologia no sistema cardiovascular, e pode ser induzida em resposta ao aumento da pressão arterial de forma crônica, doenças com sobrecarga de volume sanguíneo (anormalidade valvular do coração), infarto agudo do miocárdio, isquemia associada a doenças coronárias, entre outros. O coração em resposta ao aumento crônico de pressão arterial possui um mecanismo adaptativo inicial, onde existe um aumento da massa muscular cardíaca para normalizar o estresse presente nas paredes do coração, permitindo uma função cardiovascular normal em repouso. Porém, se o estresse crônico nas paredes continuar, o coração hipertrofiado pode dilatar, sua funcionalidade diminuir, levando a falência cardíaca (Bernardo et al., 2010).

Assim como a hipertrofia fisiológica, a hipertrofia patológica também pode exibir dois tipos de hipertrofia em resposta a diferentes estímulos. Em estímulos patológicos em que existe uma sobrecarga na pressão arterial (hipertensão, estenose aórtica), o coração se adapta exibindo hipertrofia concêntrica, com aumento na espessura da parede cardíaca, diminuição na cavidade ventricular e consequente diminuição da funcionalidade cardíaca. Já em estímulos onde está presente a sobrecarga de volume sanguíneo (regurgitação aórtica, fístulas arteriovenosas), o coração exibe a hipertrofia excêntrica, com paredes mais finas, cavidade ventricular aumentada e consequente queda de funcionalidade cardíaca (Grossman et al., 1975). Existem estudos que sugerem que a hipertrofia excêntrica induzida por estímulo patológico possui maiores riscos do que a hipertrofia cardíaca concêntrica (Berenji et al., 2005).

Em reposta a estímulos patológicos, algumas alterações celulares e moleculares mediam as adaptações deletérias do coração, como a apoptose celular, sendo que a perda de miócitos é 
substituída por colágeno excessivo (fibrose). O acúmulo de fibrose enrijece o ventrículo, prejudicando a contração e relaxamento muscular, a transdução dos sinais elétricos e a densidade capilar. Por fim, acumulo de fibrose e a reduzida densidade capilar, diminui o aporte sanguíneo para o coração, desenvolvendo isquemia do miocárdio, mostrando assim a evolução da hipertrofia para a falência cardíaca (Gunasinghe e Spinale, 2004). Existem certas vias moleculares que parecem mediar essas adaptações, como a cascata de sinalização estimulada pela angiotensina II e catecolaminas, onde ativam o GPCR ( $G$ protein-coupled receptors) e suas proteínas alvo. Algumas outras proteínas também parecem participar, como a PI3K(p110gama), MAPKs (mitogen activated protein kinases), PKC (protein kinase C) e calcineurina. Além disso, a reativação de certos genes fetais: ANF (atrial natriuretic factor), MHC (beta-myosin heavy chain), Sk. Actin (skeletal actin) demonstram ser características exclusivas da hipertrofia patológica (Bernardo et al., 2010).

A seguinte tabela resume as principais características da hipertrofia fisiológia e patológica do músculo cardíaco:

Tabela 1. Resumo das principais características da hipertrofia fisiológica e patológica no músculo cardíaco (Bernardo et al., 2010).

\begin{tabular}{lll}
\hline Característica & Hipertrofia cardíaca patológica & Hipertrofia cardíaca fisiológica \\
\hline Estímulo & Doença & Treinamento aeróbio \\
& Sobrecarga de volume ou pressão & Crescimento pós-natal \\
Cardiomiopatia & Gravidez \\
Morfologia cardíaca & Aumento do volume de miócitos & Aumento do volume de miócitos \\
& Formação de novos sarcômeros & Formação de novos sarcômeros \\
& Aumento no tamanho do coração & Aumento no tamanho do coração \\
Fibrose cardíaca & Sim & Não \\
Apoptose & Sim & Não \\
& Aumento na expressão de ANP, & \\
Expressão de genes fetais & BNP, MHC e Sk. Actin & Relativamente sem alteração \\
& & \\
Expressão de genes relacionados & Diminuição de SERCA2a & Normal ou aumentada \\
a função contrátil & & \\
Função cardíaca & Diminuída & Normal ou aumentada \\
Metabolismo & Diminui oxidação de ácidos graxos & Aumenta oxidação de ácidos graxos \\
Reversível & Aumenta utilização de glicose & Aumenta utilização de glicose \\
Asssociado a falência cardíaca & Não & Sim \\
\hline & Sim & Não \\
\hline
\end{tabular}




\section{OBJETIVOS}

\subsection{Geral}

O principal objetivo da presente dissertação foi verificar as respostas inflamatórias e hipertróficas do músculo cardíaco no estado de overreaching não funcional.

\subsection{Específico}

Comparar os efeitos do protocolo de OT proposto por Pereira e colaboradores (Pereira et al., 2012), realizado em delive com outros dois protocolos de mesmo volume e intensidade, mas realizados em aclive e sem inclinação nos seguintes parâmetros:

a) Desempenho físico, peso corporal e ingestão alimentar;

b) Conteúdo protéico e ativação das proteínas relacionadas a hipertrofia fisiológica do músculo cardíaco de camundongos - AKT (protein kinase B), 4EBP1 (4E binding protein), mTOR, S6K (ribosomal S6 kinase) e S6RP (S6 ribosomal protein);

c) Conteúdo protéico das citocinas pró-inflamatórias IL-1beta, IL-6 e TNF-alfa em músculo cardíaco de camundongos;

d) Conteúdo de fibrose intersticial no músculo cardíaco;

e) Expressão dos genes fetais (ANF - atrial natriuretic factor, MHC - beta-myosin heavy chain e Sk. Actin - skeletal actin) no músculo cardíaco;

Com o intuito de verificar a relação dos parâmetros destacados acima com o desempenho físico dos camundongos, além dos três grupos em OT, também foram avaliados roedores submetidos ao protocolo de treinamento (TR) proposto por Ferreira e colaboradores (Ferreira et al., 2007), que está associado com o aumento do desempenho físico no teste de carga incremental e exaustivo. 


\section{MATERIAL E MÉTODOS}

\subsection{Animais experimentais}

Foram utilizados 90 camundongos C57BL/6 com 8 semanas de vida provenientes do Biotério Central do Campus de Ribeirão Preto-USP. Os animais foram mantidos em gaiolas de polietileno individuais sob condições controladas de ciclo claro-escuro (12/12h), com livre acesso à água e ração convencional. Os camundongos foram divididos em 6 grupos: Naíve $(\mathrm{N}$; $\mathrm{n}=15$; camundongos sedentários), Controle ( $\mathrm{C} ; \mathrm{n}=15$; camundongos sedentários submetidos aos testes físicos), Treinado (TR; $n=15$; camundongos submetidos ao protocolo de treinamento), Overtraining em declive (OTR/down; $\mathrm{n}=15$; camundongos submetidos ao protocolo de overtraining em declive), Overtraining em aclive (OTR/up; n=15; camundongos submetidos ao protocolo de overtraining em aclive) e Overtraining sem inclinação (OTR; n=15; camundongos submetidos ao protocolo de overtraining sem inclinação).

\subsection{Teste de carga incremental}

Os animais foram adaptados ao exercício em esteira rolante durante 5 dias, 10min/dia na velocidade de $3 \mathrm{~m} / \mathrm{min}$. Conforme padronizado por Ferreira e colaboradores (Ferreira et al., 2007), o teste de carga incrementalfoi iniciado na velocidade de $6 \mathrm{~m} / \mathrm{min}$, com $0 \%$ de inclinação e incrementos de $3 \mathrm{~m} / \mathrm{min}$ a cada $3 \mathrm{~min}$ até a exaustão voluntária dos camundongos, que ocorreu quando os mesmos encostarem 5 vezes no final da esteira no intervalo de $1 \mathrm{~min}$. A potência máxima (Pmax), definida como a velocidade ( $\mathrm{m} / \mathrm{min})$ de exaustão do animal, foi utilizada para a prescrição de intensidade nos protocolos de TR, OTR/down, OTR/up e OTR. A inclinação da esteira no teste de carga incremental foi compatível com a especificidade de cada grupo experimental, ou seja, OTR/down foi avaliado em declive, TR e OTR sem inclinação, e OTR/up em aclive.

\subsection{Protocolo de treinamento (TR)}

O protocolo de treinamento foi baseado no estudo de Ferreira e colaboradores (Ferreira et al., 2007) composto por 8 semanas. Cada semana experimental foi composta por 5 dias consecutivos de treinamento e 2 dias de repouso. A tabela 2 apresenta as características de intensidade, volume, frequência, inclinação e intervalo entre as sessões de treinamento. 
Tabela 2. Protocolo de treinamento.

\begin{tabular}{cccccc}
\hline Semana & $\begin{array}{c}\text { Intensidade } \\
(\text { \%Pmax })\end{array}$ & $\begin{array}{c}\text { Volume } \\
(\mathbf{m i n})\end{array}$ & $\begin{array}{c}\text { Sessões } \\
\text { diárias }\end{array}$ & $\begin{array}{c}\text { Inclinação } \\
(\boldsymbol{\%})\end{array}$ & $\begin{array}{c}\text { Intervalo entre as } \\
\text { sessões (h) }\end{array}$ \\
\hline 1 & 60 & 15 & 1 & 0 & 24 \\
2 & 60 & 30 & 1 & 0 & 24 \\
3 & 60 & 45 & 1 & 0 & 24 \\
4 & 60 & 60 & 1 & 0 & 24 \\
$5-8$ & 60 & 60 & 1 & 0 & 24 \\
\hline
\end{tabular}

\subsection{Protocolo de overtraining em declive (OTR/down)}

O protocolo de OTR/down foi baseado no estudo de Pereira e colaboradores (Pereira et al., 2015a), e composto por 8 semanas. Cada semana experimental foi composta por 5 dias consecutivos de treinamento e 2 dias de repouso. A tabela 3 apresenta as características de intensidade, volume, freqüência, inclinação e intervalo entre as sessões do protocolo do OTR/down.

Tabela 3. Protocolo de overtraining em declive.

\begin{tabular}{cccccc}
\hline Semana & $\begin{array}{c}\text { Intensidade } \\
(\% \text { Pmax })\end{array}$ & $\begin{array}{c}\text { Volume } \\
(\mathbf{m i n})\end{array}$ & $\begin{array}{c}\text { Sessões } \\
\text { diárias }\end{array}$ & $\begin{array}{c}\text { Inclinação } \\
(\boldsymbol{\%})\end{array}$ & $\begin{array}{c}\text { Intervalo entre as } \\
\text { sessões (h) }\end{array}$ \\
\hline 1 & 60 & 15 & 1 & 0 & 24 \\
2 & 60 & 30 & 1 & 0 & 24 \\
3 & 60 & 45 & 1 & 0 & 24 \\
4 & 60 & 60 & 1 & 0 & 24 \\
5 & 60 & 60 & 1 & -14 & 24 \\
6 & 70 & 60 & 1 & -14 & 24 \\
7 & 75 & 75 & 1 & -14 & 24 \\
8 & 75 & 75 & 2 & -14 & 4 \\
\hline
\end{tabular}

\subsection{Protocolo de overtraining em aclive (OTR/up)}

O protocolo de OTR/up foi baseado no estudo de Pereira e colaboradores (Pereira et al., 2015a), e composto por 8 semanas. Cada semana experimental foi composta por 5 dias consecutivos de treinamento e 2 dias de repouso. A tabela 4 apresenta as características de intensidade, volume, freqüência, inclinação e intervalo entre as sessões do protocolo do OTR/up. 
Tabela 4. Protocolo de overtraining em aclive.

\begin{tabular}{cccccc}
\hline Semana & $\begin{array}{c}\text { Intensidade } \\
(\text { \% Pmax })\end{array}$ & $\begin{array}{c}\text { Volume } \\
(\mathbf{m i n})\end{array}$ & $\begin{array}{c}\text { Sessões } \\
\text { diárias }\end{array}$ & $\begin{array}{c}\text { Inclinação } \\
(\boldsymbol{\%})\end{array}$ & $\begin{array}{c}\text { Intervalo entre as } \\
\text { sessões }(\mathbf{h})\end{array}$ \\
\hline 1 & 60 & 15 & 1 & 0 & 24 \\
2 & 60 & 30 & 1 & 0 & 24 \\
3 & 60 & 45 & 1 & 0 & 24 \\
4 & 60 & 60 & 1 & 0 & 24 \\
5 & 60 & 60 & 1 & 14 & 24 \\
6 & 70 & 60 & 1 & 14 & 24 \\
7 & 75 & 75 & 1 & 14 & 24 \\
8 & 75 & 75 & 2 & 14 & 4 \\
\hline
\end{tabular}

\subsection{Protocolo de overtraining sem inclinação (OTR)}

O protocolo de OTR foi baseado no estudo de Pereira e colaboradores (Pereira et al., 2015a), e composto por 8 semanas. Cada semana experimental foi composta por 5 dias consecutivos de treinamento e 2 dias de repouso. A tabela 5 apresenta as características de intensidade, volume, frequiência, inclinação e intervalo entre as sessões do protocolo do OTR.

Tabela 5. Protocolo de overtraining sem inclinação

\begin{tabular}{cccccc}
\hline Semana & $\begin{array}{c}\text { Intensidade } \\
(\% \text { Pmax })\end{array}$ & $\begin{array}{c}\text { Volume } \\
(\mathbf{m i n})\end{array}$ & $\begin{array}{c}\text { Sessões } \\
\text { diárias }\end{array}$ & $\begin{array}{c}\text { Inclinação } \\
(\boldsymbol{\%})\end{array}$ & $\begin{array}{c}\text { Intervalo entre as } \\
\text { sessões }(\mathbf{h})\end{array}$ \\
\hline 1 & 60 & 15 & 1 & 0 & 24 \\
2 & 60 & 30 & 1 & 0 & 24 \\
3 & 60 & 45 & 1 & 0 & 24 \\
4 & 60 & 60 & 1 & 0 & 24 \\
5 & 60 & 60 & 1 & 0 & 24 \\
6 & 70 & 60 & 1 & 0 & 24 \\
7 & 75 & 75 & 1 & 0 & 24 \\
8 & 75 & 75 & 2 & 0 & 4 \\
\hline
\end{tabular}

\subsection{Avaliação do desempenho físico}

A avaliação do desempenho físico dos camundongos ocorreu antes do início dos protocolos experimentais e 48h após as últimas sessões dos protocolos TR, OTR/down, OTR e OTR/up nas semanas 4 e 8, e foi composto pelo teste do rotarod (Junior et al., 2012), teste de carga incremental (Da Rocha et al., 2016), teste exaustivo (Da Rocha et al., 2016) e teste de força de preensão (Junior et al., 2012). 


\subsubsection{Teste do rotarod}

48h após as últimas sessões dos protocolos experimentais, o teste do rotarod foi realizado. Nesse teste, o aparelho foi programado para apresentar velocidade inicial de 1rpm e final de 40rpm que foi alcançada 300s após o início do movimento. A aceleração durante todo teste foi constante, sendo realizadas três tentativas por animal, com intervalo de 10s, e o tempo (s) até a queda de cada animal registrado. 4h após a realização do teste do rotarod, os roedores realizaram o teste de carga incremental.

\subsubsection{Teste exaustivo}

24h após a realização do teste de carga incremental, os camundongos correram na velocidade de $36 \mathrm{~m} / \mathrm{min}$ com inclinação de $8 \%$ até exaustão voluntária, que ocorreu quando os mesmos encostaram 5 vezes no final da esteira no intervalo de $1 \mathrm{~min}$.

\subsubsection{Teste de força de preensão}

4h após a realização do teste exaustivo, os camundongos realizaram o teste de força de preensão com a grade não inclinada. Foram realizadas três tentativas de preensão com as patas dianteiras e traseiras sem que os valores fossem considerados. Cada tentativa consistiu em tensionar o animal pela cauda, de modo que ambas as patas (dianteiras e traseiras) passassem por todos os arames da grade e o roedor se desprende-se da mesma. Posteriormente, foram realizadas tentativas válidas e os três maiores valores de tensão aplicados foram registrados em Newton (N) (Junior et al., 2012).

\subsection{Avaliação de parâmetros metabólicos}

Os camundongos dos grupos N, C, TR, OTR/down, OTR/up e OTR foram avaliados diariamente quanto à variação do peso corporal e ingestão alimentar. A ingestão alimentar diária foi mensurada através da subtração do peso da ração final (peso da ração restante em cada gaiola individual ao final de $24 \mathrm{~h}$ ) pelo peso da ração inicial (peso da ração colocada em cada gaiola individual $24 \mathrm{~h}$ antes do peso da ração final).

\subsection{Extração do músculo cardíaco e sangue}

Trinta e seis horas após o teste de força de preensão realizado ao final da oitava semana de aplicação dos protocolos experimentais, e em jejum de aproximadamente $12 \mathrm{~h}$, os animais dos grupos N, C, TR, OTR/down, OTR/up e OTR foram anestesiados através da administração intraperitoneal de xilazina (10 mg/kg peso corporal) e quetamina $(100 \mathrm{mg} / \mathrm{kg}$ 
peso corporal) misturadas na mesma seringa. $\mathrm{O}$ controle da anestesia foi avaliado pela perda do reflexo podal (Pauli et al., 2008). Posteriormente, os animais foram decapitados e o sangue coletado para análise da CK-MB sérica. Imediatamente após a decapitação, os corações foram retirados e os ventrículos esquerdos isolados para serem armazenados a $-80^{\circ} \mathrm{C}$ para análise subseqüente dos conteúdos e ativação das proteínas pela técnica de immunoblotting e RTPCR.

\subsection{Análise de CK-MB sérica}

Após a coleta do sangue, as amostras foram centrifugadas em uma velocidade de 3.500rpm, por 15 minutos a $4^{\circ} \mathrm{C}$. O soro obtido foi utilizado em análise por kit bioquímico segundo especificações do fabricante (LaborLab ${ }^{\circledR}$, SP. Brasil).

\subsection{Immunoblotting}

As amostras do ventrículo esquerdo foram homogeneizadas com Tissue-Tearor (model 985370 variable speed; Biospec products, inc) em tampão de extração RIPA a $4^{\circ} \mathrm{C}$ com um Polytron PTA 20S gerador (Brinkmann Instruments modelo PT 10/35), operado a uma velocidade máxima de 30s. Os extratos foram centrifugados $(9900 \mathrm{~g})$ durante 40 minutos a $4^{\circ}$ C para remover o material insolúvel, e os sobrenadantes destes homogeneizados foram utilizados para quantificação de proteínas utilizando o método de Bradford (Bradford, 1976).

As proteínas foram desnaturadas por fervura em tampão de amostra de Laemmli (Laemmli, 1970) contendo DTT 100mM, executado em gel SDS-PAGE e transferidas para membranas de nitrocelulose (GE Healthcare, Hybond ECL, RPN303D). A eficiência da transferência para membranas de nitrocelulose foi verificada por coloração breve das bandas com Ponceau. Estas membranas foram então bloqueadas com solução salina tamponada com Tris (TBS) contendo 5\% de BSA e 0,1\% de Tween-20, durante 1 hora, a $4^{\circ} \mathrm{C}$. Posteriormente, as membranas foram incubadas overnight com anticorpo específico (anti-4EBP1, phospho4EBP1, anti-AKT, phospho-AKT, anti-mTOR, phospho-mTOR, anti-S6k, phospho-S6k, antiS6RP, phospho-S6RP, anti IL-1beta, anti-IL-6, anti-TNF-alfa e anti-beta actina). 16h após a incubação com anticorpo primário foram realizadas 5 lavagens de 5 min com TBS contendo $0,1 \%$ de tween-20, posteriormente todas as membranas foram incubadas durante 1 hora a $4^{\circ} \mathrm{C}$ com anticorpo secundário. As bandas imunorreativas específicas foram detectadas por chemilumininescence (GE Healthcare, ECL Plus Western Blotting Detection System, RPN2132). As imagens foram adquiridas por ChemiDoc XRS Imaging System (BioRad) e quantificados utilizando software Image Lab 3.0. Os anticorpos foram provenientes das 
empresas Cell Signalling Technology (Cell Signalling Technology, MA, USA), Santa Cruz Biotechnology (Santa Cruz Biotechnology Inc., CA, USA) e Upstate Biotechnology (Upstate Biotechnology, NY, USA), de acordo com a disponibilidade. Os reagentes químicos de rotina foram provenientes da Sigma Chemical Corporation (St. Louis, MO, USA).

\subsection{Avaliação da fibrose intersticial no miocárdio}

36h após a avaliação do desempenho físico na $8^{\circ}$ semana de treino, foi realizado a coleta do músculo cardíaco com subsequente separação do ventrículo esquerdo. Secções do ventrículo esquerdo $(5 \mu \mathrm{m})$ foram colocadas em lâminas próprias para histologia. Nessas técnicas, as lâminas contendo o material foram colocadas em xilol e posteriormente hidratadas em álcool em concentrações decrescentes, lavadas em água corrente e posteriormente coradas com corante Masson's trichrome. Foram capturadas imagens com o auxílio de uma câmera QColor5 Olympus, nas objetivas de 100x e 400x em microscópio. Para quantificar o montante de fibrose tecidual, foi utilizado o programa ImageJ, determinando a porcentagem entre os píxeis azuis (tecido com fibrose) x pixeis não-azuis (tecido sem fibrose) (Song et al., 2010).

\subsection{Real Time-Polymerase Chain Reverse (PCR)}

As amostras do ventrículo esquerdo foram retiradas após 36h da última avaliação do desempenho físico. O RNA total do ventrículo esquerdo será extraído com TRIZOL (Invitrogen, Carlsbad, CA). A reação de transcrição reversa ( $1 \mu \mathrm{g}$ do RNA total) foi realizada utilizando o Superscript III Reverse Transcriptase e outros Primers (Invitrogen). Para realização do Real Time-PCR será utilizada oligonucleotídeos TaqMan (Applied Biosystems) para ANF (atrial natriuretic factor), MHC (beta-myosin heavy chain) e Sk. Actin (skeletal muscle actin). Todos os valores serão corrigidos pelo valor obtido na amplificação do GAPDH (Glyceraldehyde-3-phosphate dehydrogenase) (Kemi et al., 2008).

\subsection{Análise dos resultados}

Os resultados foram expressos em média \pm erro padrão médio. A análise de variância (ANOVA) foi utilizada para verificar os efeitos dos protocolos TR, OTR/down, OTR/up e OTR nos parâmetros estudados. Quando a análise de variância indicou significância, o teste post hoc de Bonferroni foi utilizado. O teste t de Student não pareado foi utilizado para realizar comparações planejadas entre dois grupos quando necessário, e o teste t pareado foi utilizado para comparar a variação do desempenho dos grupos entre as semanas 4 e 8 . Foi adotado o nível de significância $\mathrm{p} \leq 0.05$. 


\section{RESULTADOS}

$\mathrm{Na}$ figura 1.A podemos verificar a variação do peso corporal em toda as semanas experimentais. O grupo TR apresentou menor variação nas semanas 3 e 4 quando comparado com o grupo N. Já na semana 6 e 7 ambos os grupos TR e OTR/down apresentaram diferença para o grupo $\mathrm{N}$, e na semana 8 somente o grupo OTR/down apresentou menor variação do peso corporal quando comparado ou grupo N. Na figura 1.B é possível verificar a ingestão alimentar total de todos os grupos experimentais entre as semana 0 e 4, 4 e 8 , e 0 e 8 . Entre as semanas 4 e 8 o grupo TR apresentou menor ingestão alimentar em comparação com os grupos N, CT, OTR/up e OTR, já na ingestão alimentar referente a todo o período experimental (semana 0 a 8) o gupo TR apresentou menor ingestão alimentar somente quando comparado com os grupos OTR/up e OTR.

$\mathbf{A}$

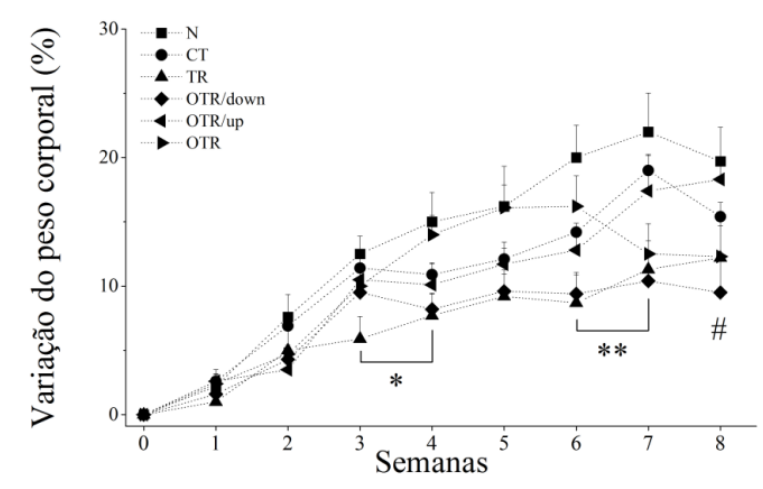

B

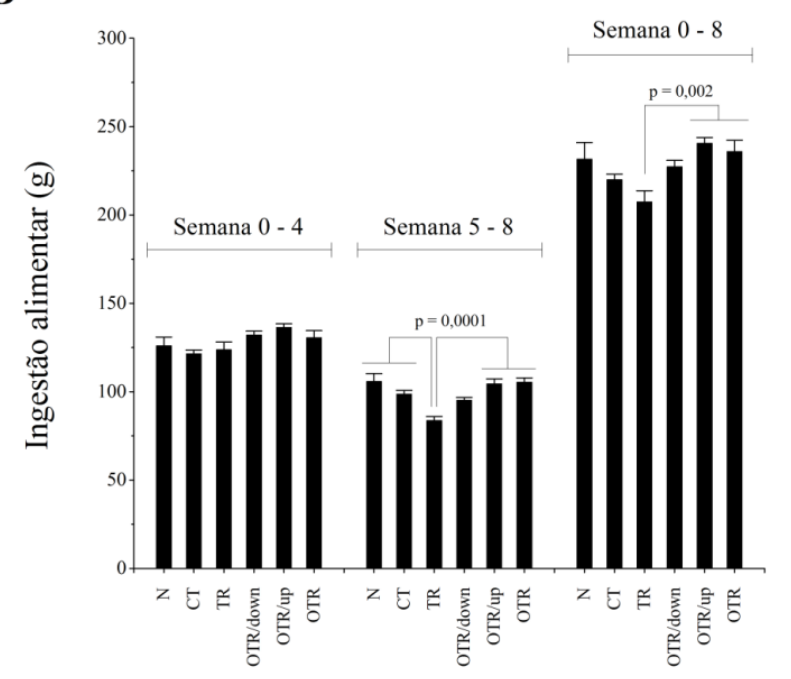

Figura 1. Parâmetros metabólicos. A) Variação do peso corporal; B) Ingestão alimentar; * $\mathrm{p}<0.05$ TR $v s$ N; ** $\mathrm{p}<0.05$ TR e OTR/down vs $\mathrm{N}$; \# $\mathrm{p}<0.05$ OTR/down $v s \mathrm{~N} . \mathrm{n}=10$ camundongos. 
Nas figuras 2.A, 2.B, 2.C e 2.D é possível verificar que os grupos submetidos aos protocolos de OT apresentaram queda de desempenho na semana 8 quando comparado a semana 4 em todos os testes físicos realizados. Já o grupo TR apresentou aumento de performance em todos os testes físicos, porém somento no teste de carga incremental e de força de preeensão apresentou diferença significativa na semana 8 quando comparado a semana 4.
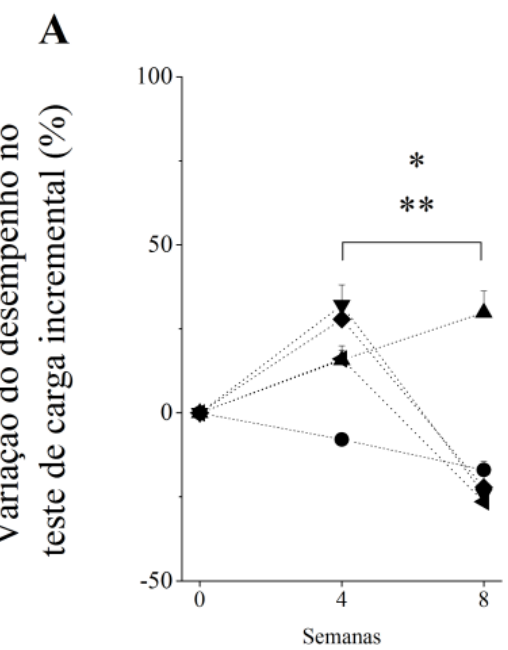

C

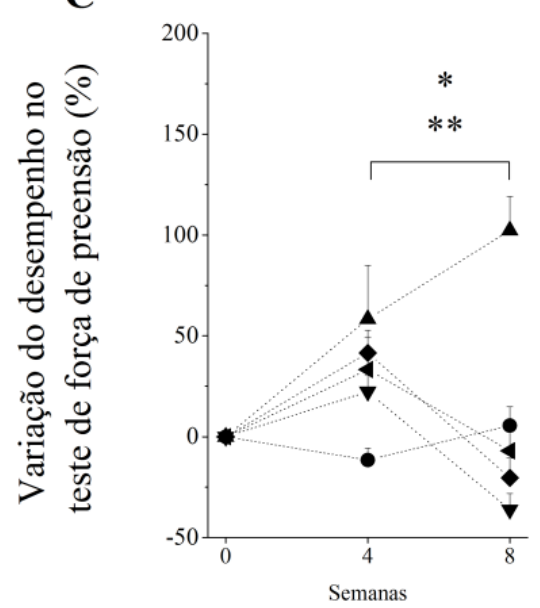

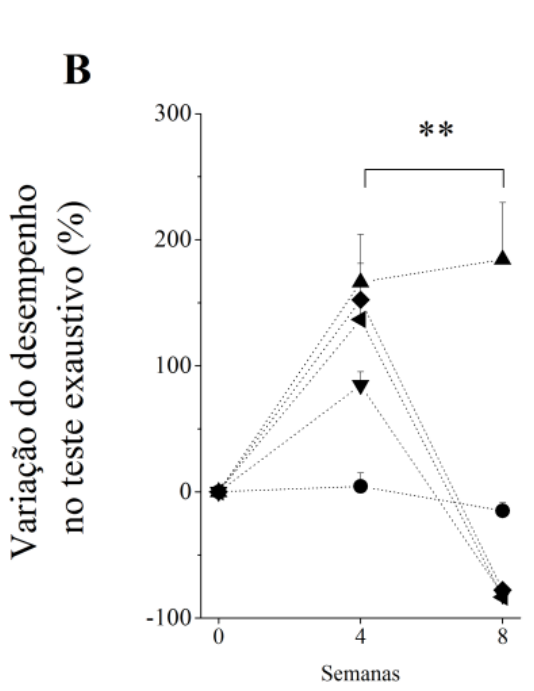

D

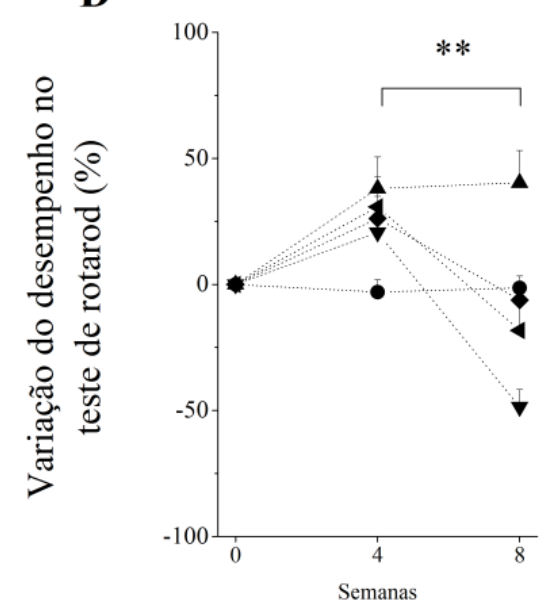

Figura 2. Desempenho nos testes físicos. A) teste de carga incremental; B) teste exaustivo; C) teste de força de preensão; D) teste de rotarod. * $\mathrm{p}<0.05$ TR semana $4 v s$ semana $8 ; * * \mathrm{p}<0.05$ OTR/down, OTR/up e OTR semana 4 vs semana 8 . $\mathrm{n}=10$ camundongos.

Na figura 3.A está demosntrado a razão entre o peso do ventrículo esquerdo e o peso total do coração. Todos os grupos que passaram por protocolos de treinamento e OT apresentaram aumento significtivo nessa razão quando comparados aos grupos sedentários ( $\mathrm{N}$ e CT). Na figura 3.B está apresentada a atividade da enizima creatina quinase isoenzima $\mathrm{MB}$, 
sendo que os grupos CT, TR, OTR/down e OTR apresentaram aumento significativo quando comparados ao grupo $\mathrm{N}$.

A

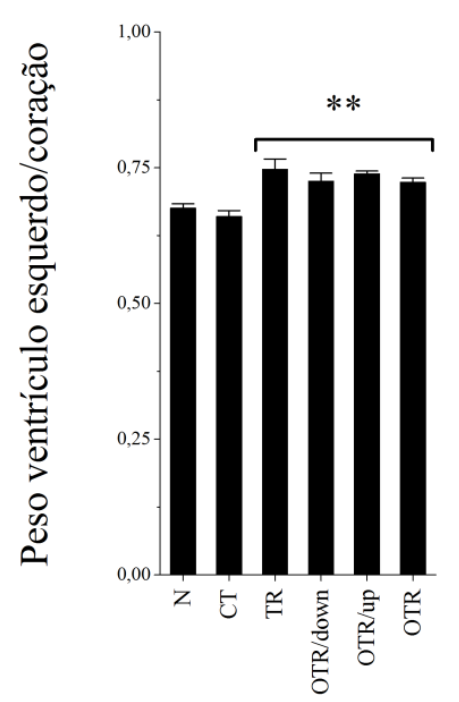

B

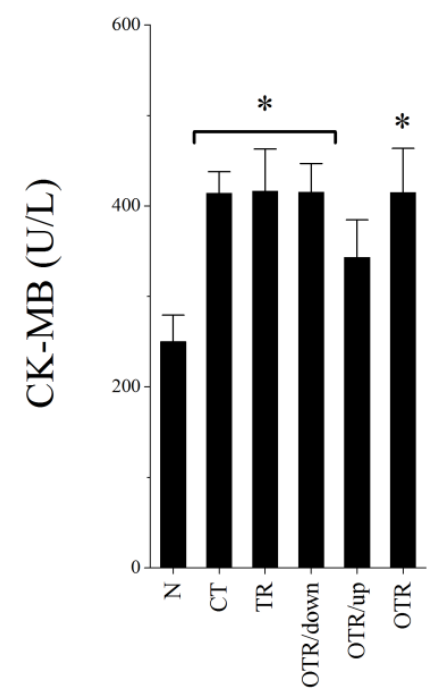

Figura 3. (A) Razão entre o peso do ventrículo esquerdo e o peso total do coração; (B) Atividade da enzima CK-MB no soro; ** $\mathrm{p}<0.05$ vs N e CT; * $\mathrm{p}<0.05$ vs $\mathrm{N} . \mathrm{n}=5-7$ camundongos.

Na figura 4 está apresentado os níveis das citocinas pró-inflamatórias no ventrículo esquerdo. Não foram encontradas diferença significativas entre os grupos experimentais. Somente quando é realizada uma comparação planejada entre dois grupos específicos, é possível verificar maior conteúdo de IL-1beta madura no grupo OTR/down quando comparado ao grupo CT (figura 4.B).

Já na figura 5 está demosntrado os níveis de ativação das proteínas relacionadas a via da mTOR O grupo OTR/down apresentou maiores valores da razão p-S6RP/S6RP quando comparado aos grupos N,CT e TR (figura 5.D). Todos os grupos submetidos aos protocolos de OT apresentaram redução na ativação da proteína AMPKalfa (p-AMPKalfa/AMPKalfa) quando comparados ao grupo TR (figura 5.F). Quando realizada uma comparação planejada, o grupo OTR/down apresentou menor ativação da proteína mTOR (p-mTOR/mTOR) comparado ao grupo CT (figura 5.B). As outras proteínas relacionadas a via de sinalização da mTOR não sofreram modulações.

Na figura 6.A e 6.B está apresentado o conteúdo total das protéinas mTOR e S6RP, respectivamente. Os grupos CT e OTR/down apresentaram menor contéudo da mTOR total quando comparados aos grupos N e TR, já em relação ao conteúdo da proteína S6RP total, o grupo OTR/down apresentou redução quando comparado ao grupo $\mathrm{N}$. 
Em relação a análise histológica, é possível verificar aumento do tecido conjuntivo no ventrículo esquerdo de todos os grupos submetidos aos protocolos de OT quando comparados aos grupos N e TR (figura 7.G). Somento os grupos OTR/up e OTR apresentam diferença significativa quando comparado ao grupo CT.

Na figura 8 está apresentado os níveis de RNA mensageiro dos genes ANF, beta-MHC e Sk. Actin. O grupo OTR/down apresentou aumento significativo na expressão do gene betaMHC quando comparado ao grupo TR.

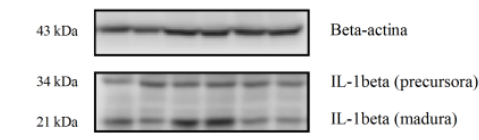

\section{A}

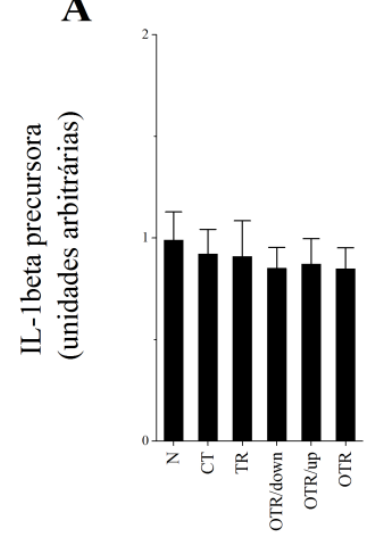

B
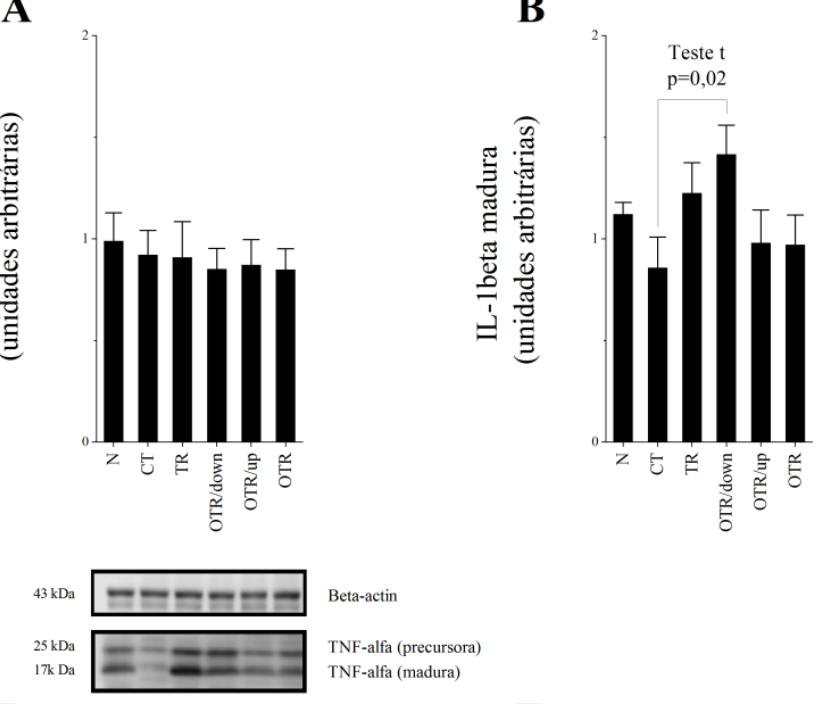

D

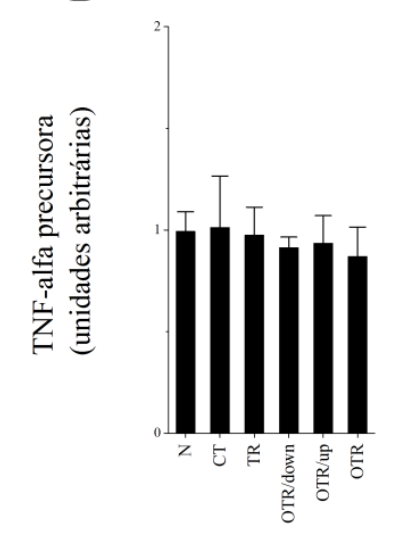

$\mathbf{E}$

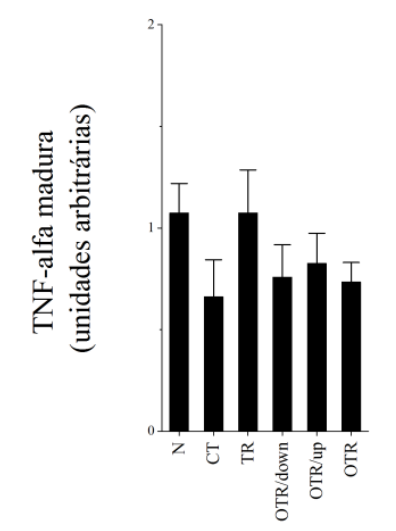

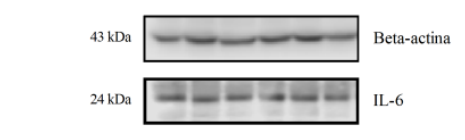

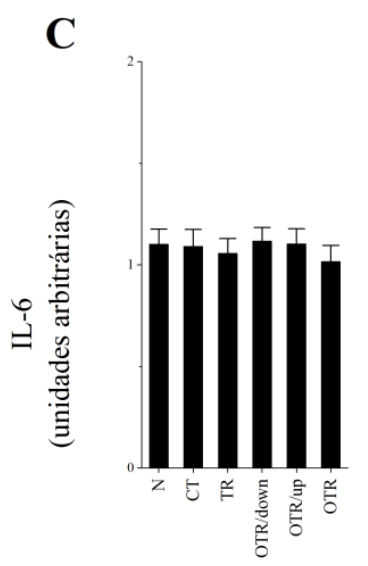

Figura 4. Níveis protéicos de (A) IL-1beta precursora, (B) IL-1beta madura, (C) IL-6, (D) TNFalfa precurora e (E) TNF-alfa madura no ventrículo esquerdo. $n=5-7$ camundongos. 
A $60 \mathrm{k}$

Akt toal

$60 \mathrm{KDa}$
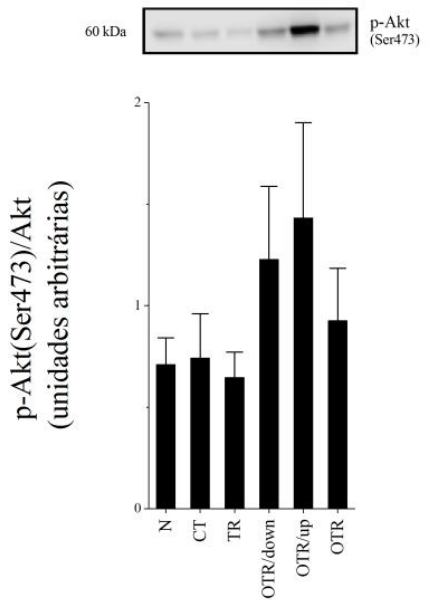

D
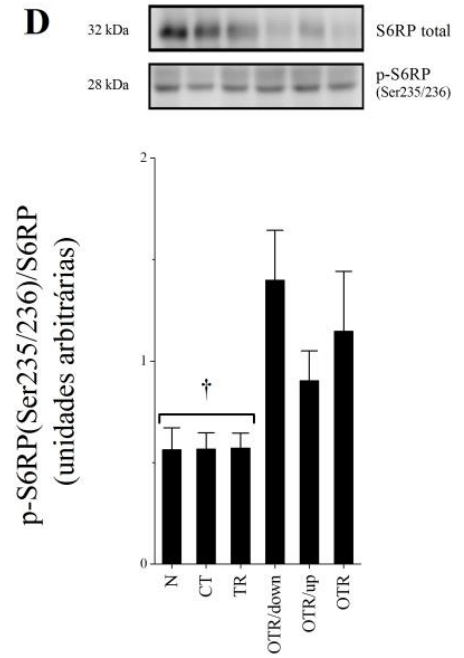

B

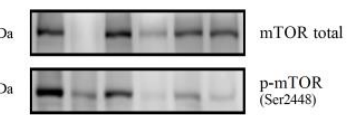

$289 \mathrm{kDa}$

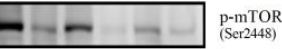
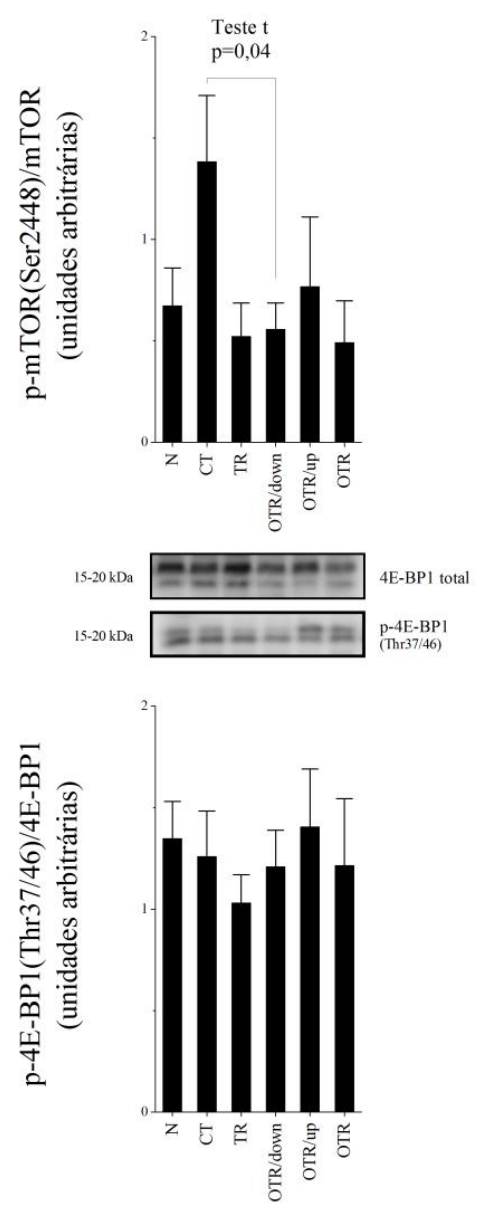
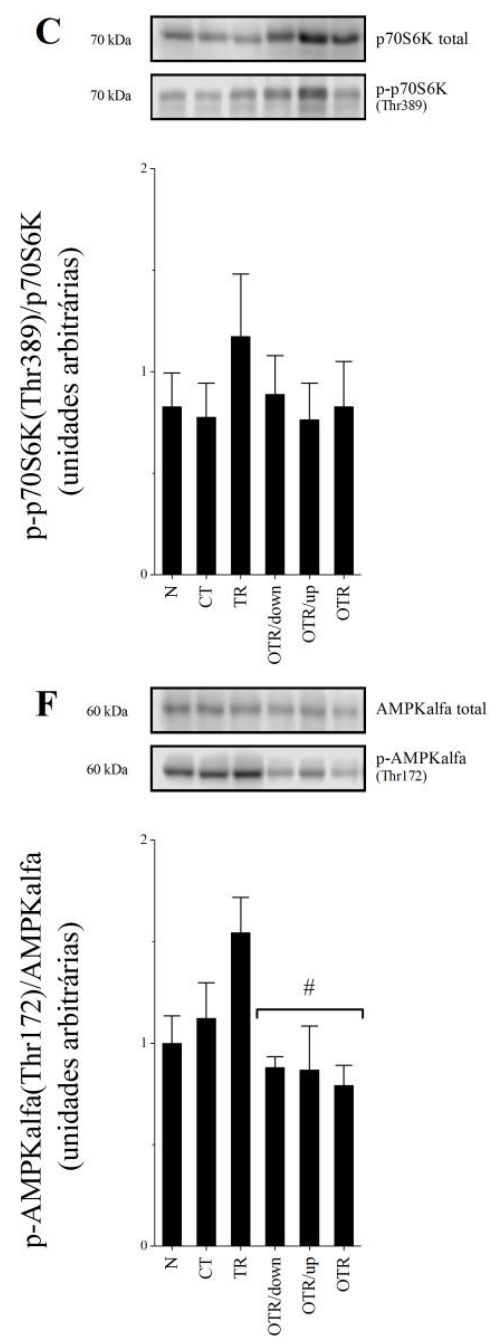

Figura 5. Níveis protéicos de (A) p-Akt/Akt, (B) p-mTOR/mTOR, (C) p-p70S6K/p70S6K, (D) p-S6RP/S6RP, (E) p-4E-BP1/4E-BP1 e (F) p-AMPKalfa/AMPKalfa no ventrículo esquerdo. $\dagger$ $\mathrm{p}<0.05$ vs OTR/down; \# $\mathrm{p}<0.05$ vs TR. $\mathrm{n}=5-7$ camundongos. 


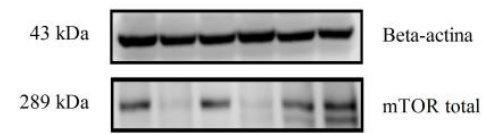

A

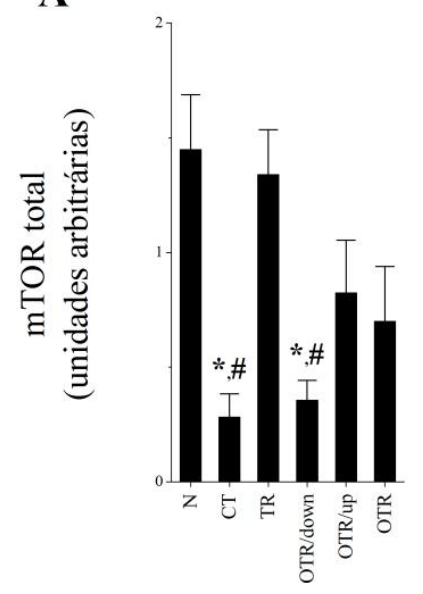

$43 \mathrm{kDa}$

$28 \mathrm{kDa}$

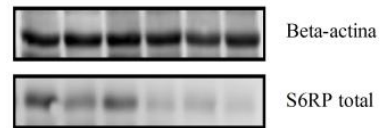

B

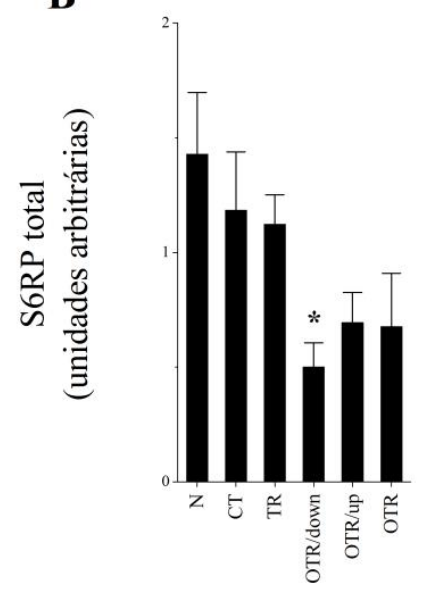

Figura 6. Níveis protéicos de (A) mTOR total e (B) S6RP total no ventrículo esquerdo. * $\mathrm{p}<0.05$ vs $\mathrm{N}$; \# $\mathrm{p}<0.05$ vs TR. $\mathrm{n}=5-7$ camundongos.
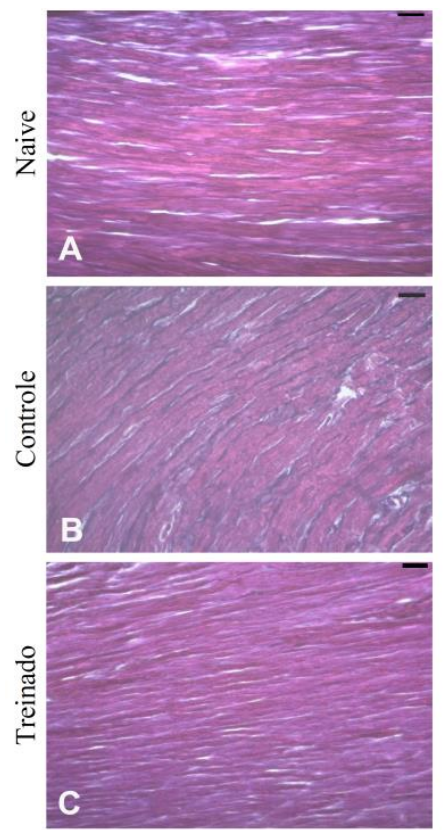
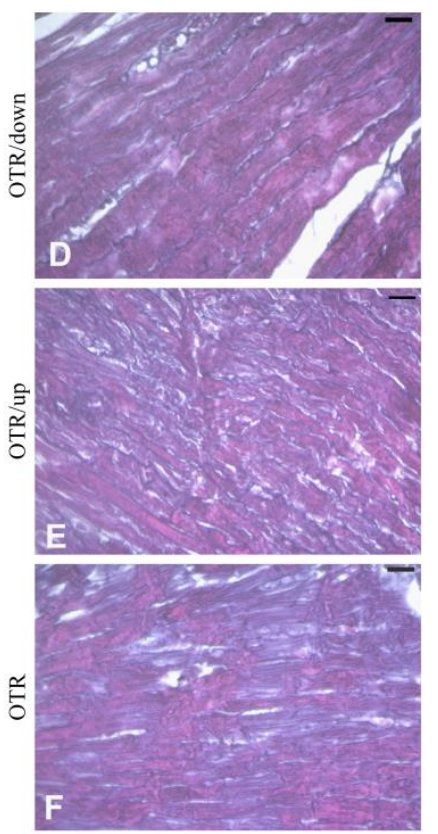

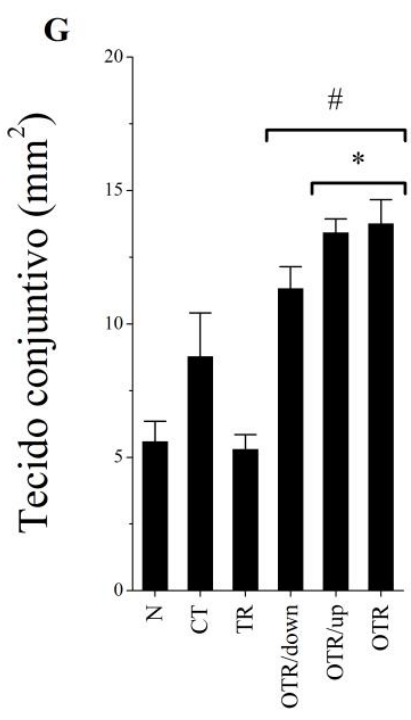

Figura 7. Análise histológica do ventrículo esquerdo. (A-F) Fotos representativas do tecido cardíaco marcado com o corante Masson's trichrome por análise histológica; (G) Conteúdo de tecido conjuntivo no ventrículo esquerdo. \# $\mathrm{p}<0.05$ vs $\mathrm{N}$ e TR; * $\mathrm{p}<0.05$ vs CT. $\mathrm{n}=4$ camundongos. 
A

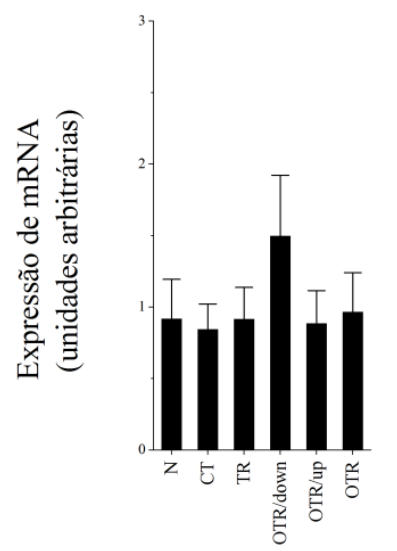

Atrial natriuretic factor (ANF)
B

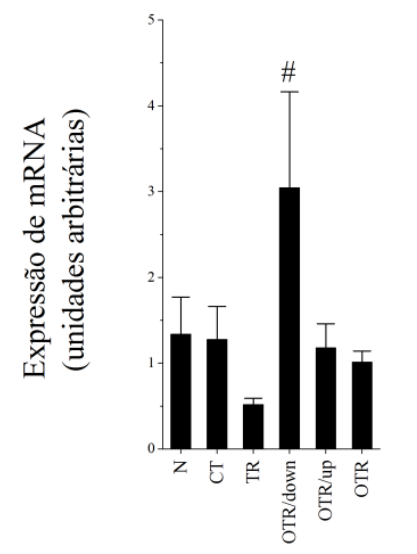

Beta-myosin heavy chain (MHC)
C

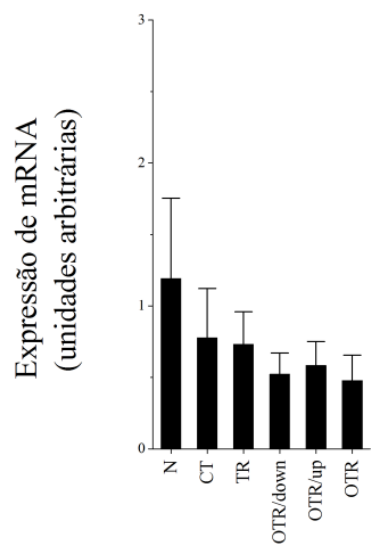

Skeletal muscle actin

Figura 8. Expressão gênica de (A) Atrial natriuretic factor, (B) Beta-myosin heavy chain e (C) Skeletal muscle actin no ventrículo esquerdo. \# $\mathrm{p}<0.05$ vs TR. $\mathrm{n}=3-4$ camundongos. 


\section{DISCUSSÃO E CONCLUSÃO}

Os principais achados da presente dissertação são: a) após a aplicação dos protocolos de OT, os grupos exibiram queda de performance similar em todos os testes físicos; b) o grupo TR exibiu ganhos de performance após o protocolo de treinamento; c) o grupo OTR/down exibiu menor variação do peso corporal após 8 semanas do protocolo de OT; d) todos os grupos que passaram pelo protocolo de treinamento e OT exibiram aumento da razão do peso do ventrículo esquerdo pelo peso total do coração; e) os grupos CT, TR, OTR/down e OTR apresentaram aumento na atividade da enzima CK-MB no soro; f) todos os protocolos de OT apresentaram indícios de fibrose no ventrículo esquerdo; g) todos os protocolos de OT apresentaram menor atividade da proteína AMPK no tecido cardíaco; h) o grupo OTR/down apresentou modulação na via de sinalização da mTOR no tecido cardíaco. i) o grupo OTR/down aumentou a expressão do gene MHC;

Estudos prévios do nosso grupo de pesquisa corroboram com os dados referentes ao peso corporal encontrados no presente estudo (Pereira, B. et al., 2014; Da Rocha et al., 2015; Pereira, B. C. et al., 2015). O grupo OTR/down demonstrou menor ganho de peso corporal comparado ao grupo sedentário, sendo que esse fenômeno pode ser decorrente da inflamação hipotalâmica encontrada em camundongos que realizaram especificamente esse protocolo de OT (Pereira et al., 2015b). Segundo Pereira et al. (Pereira et al., 2015b), o aumento da concentração de citocinas pró-inflamatórias no tecido hipotalâmico pode induzir a uma redução da ingestão alimentar, o que concomitantemente com o alto gasto energético decorrente do protocolo de OT pode levar a um balanço energético negativo, levando a menor ganho de peso corporal. Interessantemente, não foi observado redução na ingestão alimentar total desse grupo (entre as semana $0-8$ ), nem entre as últimas 4 semanas de aplicação do protocolo de OT específico (entre as semanas 5-8), reforçando os dados apresentados por Pereira et al. (Pereira et al., 2015b) em que a redução alimentar ocorre somente na última semana do protocolo de OT. Da Rocha et al. (da Rocha et al., 2016) também demonstraram que o grupo de camundongos que realizou o protocolo de OT em declive exibiu sinais de atrofia muscular, outro possível fator influenciador da menor variação de peso corporal.

Os dados de desempenho físico também corroboram com nossos estudos prévios (Pereira et al., 2015a; Pereira et al., 2015b; da Rocha et al., 2016), sendo que os grupos que realizaram o protocolo de OT apresentaram queda de performance similar. Em relação ao grupo treinado, o aumento de performance evidente em todos os testes físicos realizados, demonstra que a correta manipulação das variáveis do treinamento, como intensidade/volume/densidade 
juntamente com o tempo de recuperação adequado, promovem ganhos na performance física (Kraemer e Ratamess, 2004).

Com excessão do grupo OTR/up, todos os grupos que realizaram a bateria de testes físicos apresentaram aumento significativo da atividade da enzima CK-MB no soro. O aumento desta enzima está ligado a quadros de danos cardíacos e tipicamente é utilizada no diagnóstico de infarto agudo do miocárdio (IAM) (Goto et al., 2003). Interessantemente, já foi demonstrado em alguns estudos clássicos (Schnohr et al., 1980; Totsuka et al., 2002; Baird et al., 2012) que o aumento dessa enzima também está relacionado com a realização de exercício físico, sem possuir qualquer indicativo de IAM. Schnohr et al. (Schnohr et al., 1980) demonstraram em seu estudo que a atividade da enzima CK-MB permaneceu elevada ao fim de uma corrida de longa distância, mesmo após 20 horas de recuperação. Tanto o grupo sedentário quanto os grupos TR, OTR/down e OTR realizaram uma bateria de testes 36 horas antes da coleta das amostras de sangue, o que pode ter influenciado nos resultados elevados de CK-MB. O grupo OTR/up, apesar de não apresentar diferença significativa na atividade da CK-MB, demonstrou um aumento de aproximadamente $37 \%$ quando comparado ao grupo naíve. Sua resposta pode ter sido atenuada pela especificidade do teste físico mais intenso que compunha esse conjunto, o teste exaustivo, ser realizado com a esteira em aclive. As adaptações que ocorreram durante o protocolo de OT na subida podem ter um efeito protetor para este tipo de estímulo, provocando uma atenuação das respostas da CK.

O aumento no peso do ventrículo esquerdo dos camundongos que realizaram os protocolos de treinamento e OT, inicialmente podem ser decorrentes do mesmo estímulo, já que os 4 grupos experimentais (TR, OTR/down, OTR/up e OTR) passaram pelo mesmo protocolo de treinamento nas 4 primeiras semanas, possivelmente adotando uma característica de uma hipertrofia fisiológica, já que foram acompanhados de melhora na performance física após esse período (Bernardo et al., 2010). A partir da quinta semana os estímulos de treino se diferenciam, e os grupos que passam pelos protocolos de OT exibem uma queda de performance brusca acompanhada de acúmulo de tecido conjuntivo no coração.

Fibrose no miocárdio é uma das principais características de um remodelamente maladaptativo (Guasch e Nattel, 2013), causando enrijecimento do ventrículo, prejudicando a contração e relaxamento muscular, a transdução dos sinais elétricos e a densidade capilar (Bernardo et al., 2010). Alguns estudos já têm demonstrado que o exercício físico pode provocar tais modulações, como Guasch et al. (Guasch et al., 2013) e Benito et al. (Benito et al., 2010), que já demonstraram aumento de fibrose nos átrios e no ventrículo direito de ratos submetidos a um treinamento de alta intensidade. Alguns estudos em humanos já evidenciaram 
também algumas caracteristicas indiretas para esse tipo de adaptação (Lindsay e Dunn, 2007; Breuckmann et al., 2009; La Gerche et al., 2011; Wilhelm et al., 2011), porém os mecanismos pelo qual essa mal adaptação ocorre em resposta ao exercício físico não está bem elucidada.

Li et al. (Li et al., 2007) evidenciaram em seu estudo que a ativação da AMP-activated protein kinase (AMPK), de maneira farmacológica, preveniu o desenvolvimento de hipertrofia patológica em ratos que foram submetidos a cirurgia de constrição da aorta. Já Ma et al. (Ma et $a l ., 2015)$ verificaram que o exercício físico moderado é capaz de atenuar a fibrose cardíaca induzida por isoproterenol (agonista dos receptores beta-adrenérgicos), sendo dependente da ativação da AMPKalfa. Interessantemente, os resultados do presente trabalho evidenciam que todos os grupos que passaram pelo protocolo de OT demonstraram menor ativação da proteína AMPKalfa, sendo possível que essa alteração tenha corroborado com o aumento de tecido conjuntivo verificado por análises histológicas.

Sabe-se que a proteína AMPK possui papel regulador inibitório na via de sinalização da mTOR (Hay e Sonenberg, 2004), porém não foram encontradas diferenças na ativação das proteínas relacionadas a essa via, com excessão da proteína S6RP, que exibiu maiores valores na razão entre a S6RP fosforilada pela S6RP total no grupo OTR/down. Analisando de forma separada, os níveis de p-S6RP foram similares entre os grupos, porém o grupo OTR/down demonstrou menor conteúdo da proteína em sua forma total. A S6RP tem a função de aumentar a tradução de proteínas que compõem a maquinaria traducional, ou seja, formação ribossomal, elevando assim o nível tradução de proteínas da célula (Avni et al., 1997). O reduzido conteúdo de S6RP no grupo OTR/down pode estar relacionado a um prejuízo na tradução de proteínas, caracterizando um indício de hipertrofia patológica, já que Kemi et al. (Kemi et al., 2008) evidenciaram que a via de sinalização da mTOR possui papel crucial na hipertrofia fisiológica, mas não está presente na patológica.

Da mesma forma, os grupos CT e OTR/down apresentaram acentuada redução no conteúdo da proteína mTOR no ventrículo esquerdo, porém quando olhamos à ativação da mesma (p-mTOR/mTOR) e comparamos exclusivamente esses dois grupos, o grupo OTR/down também apresenta menor ativação ( $\mathrm{p}=0.04)$, evidenciando uma grande diferença entre esses grupos, apesar de apresentarem similar comportamento no conteúdo total dessa proteína. Possivelmente, essa maior ativação da mTOR no grupo CT, $(\sim 105 \%, 165 \%, 150 \%$, $81 \%$ e $181 \%$ comparado aos grupos N, TR, OTR/down, OTR/up e OTR, respectivamente) seja um efeito residual dos testes físicos, já que se trata de um grupo sedentário que realiza testes físicos máximos e intensos. É importante salientar que o exercício físico intenso modula positivamente a ativação da mTOR no miocárdio (Kemi et al., 2008), e seu pico de ativação 
não é instantaneamente após o término do estímulo do exercício, e sim de forma tardia (Ogasawara et al., 2014).

Song et al. (Song et al., 2010) demonstraram em um elegante estudo que a mTOR possui um importante papel cardioprotetor no desenvolvimento da hipertrofia patológica decorrente de cardiomiopatia, sendo que sua superexpressão diminui o grau de fibrose no coração, protegendo-o contra disfunções. Sendo assim, o menor conteúdo de mTOR verificado no grupo OTR/down soma em mais um indício de hipertrofia patológica que pode ter sido induzido pelo protocolo de OT em declive. Interessantemente não foram encontradas diferenças no conteúdo de citocinas pró-inflamatórias, porém quando olhamos exclusivamente para o grupo OTR/down, verificamos que ele possui maiores valores de IL-1beta madura quando comparado ao grupo CT ( $\mathrm{p}=0.02)$. No mesmo estudo, Song et al. (Song et al., 2010) demonstraram que quando super-expressada, a mTOR é capaz de reduzir os níveis de citocinas pró-inflamatórias, como a IL-1beta, em indução da patologia cardíaca. Essa inversa relação entre mTOR e citocinas pró-inflamatórias fica evidenciada nesses dois grupos, onde o grupo CT apresentou aumento na ativação da mTOR e redução do conteúdo de IL-1 beta quando comparado ao grupo OTR/down que demonstou menor conteúdo de mTOR e maior conteúdo de IL-1beta.

Quando olhamos para a expressão dos genes fetais que estão estreitamente relacionados com a hipertrofia patológica, verificamos um grande aumento da expressão do gene beta-MHC no grupo OTR/down. MHC é o principal componente da miosina, sendo um complexo de proteínas responsável pela contração de células musculares (Bernardo et al., 2010) . Morkin (Morkin, 2000) demonstrou que no coração de camundongos pré-natais, o gene beta-MHC é a principal isoforma presente, e após o nascimento, sua expressão cai e a isoforma alfa-MHC começar a ser expressada. Esse aumento da beta-MHC e diminuição da alfa-MHC é vista como uma resposta adaptativa à hipertrofia patológica, sendo que a beta-MHC possui uma atividade catalítica menor na hidrólise do ATP (reação necessária para contração dos músculo cardíaco), ocasionando em uma função contrátil mais lenta e econômica. Diversos estudos utilizando modelos de hipertrofia patológica demonstraram aumento na expressão do gene beta-MHC, e utilizam esse parâmetro para distinção da hipertrofia fisiológica (Izumo et al., 1987; Boluyt et al., 1994; Kemi et al., 2008; Bernardo et al., 2010).

Levando em consideração os dados encontrados na presente dissertação, pode-se concluir que excesso de exercício caracterizado pelos protocolos de OT foram capazes de induzir acúmulo de fibrose no ventrículo esquerdo dos camundongos, acompanhado de menor atividade da proteína AMPKalfa, e indícios de hipertrofia patológica do miocárdio. Especificamente o grupo submetido ao protocolo de OT em declive exibiu menor contéudo da 
proteína mTOR e reativação do gene fetal beta-MHC, os quais evidenciam de forma mais concreta que o excesso de exercício físico pode provocar o desenvolvimento da hipertrofia patológica, principalmente nesse modelo de OT. 


\section{ATIVIDADES REALIZADAS}

- Todos os créditos realizados (20 créditos);

- Avaliador SIICUSP (2015 e 2016);

- Ministrou um curso de capacitação para alunos do $1^{\circ}$ ano da Escola de Educação Física e Esporte, com atividades práticas e teóricas relacionadas a linha de pesquisa do grupo de estudos;

- Aprovado no exame de qualificação;

- Produção científica:

○ Downhill Running Excessive Training Inhibits Hypertrophy in Mice Skeletal Muscles with Different Fiber Type Composition (doi:10.1002/jcp.25197) Journal of Cellular Physiology, 2016;

○ Downhill Running-Based Overtraining Protocol Improves Hepatic Insulin Signaling Pathway without Concomitant Decrease of Inflammatory Proteins (doi:10.1371/journal.pone.0140020) PloS One, 2015;

- Excessive eccentric exercise leads to transitory hypothalamic inflammation, which may contribute to the low body weight gain and food intake in overtrained mice (doi:10.1016/j.neuroscience.2015.10.027) Neuroscience, 2015 ;

$\circ$ Excessive eccentric exercise-induced overtraining model leads to endoplasmic reticulum stress in mice skeletal muscles (doi:10.1016/j.lfs.2015.12.037) Life Science, 2016.

- Excessive training impairs the insulin signal transduction in mice skeletal muscles (doi: 10.1530/JOE-16-0063) The Journal of endocrinology, 2016.

- Exhaustive training leads to hepatic fat accumulation (doi: 10.1002/jcp.25625) Journal of Cellular Physiology, 2016.

$\circ$ Excessive training is associated with endoplasmic reticulum stress but not apoptosis in the hypothalamus of mice (doi: 10.1139/apnm-2016-0542) Applied Physiology, Nutrition and Metabolism, 2016.

- Aceitos para publicação:

○ Hypothalamic endoplasmic reticulum stress of overtrained mice after recovery. Motriz, Revista de Educação Física.

$\bigcirc$ Nonfunctional overreaching and hepatic adaptations of APPL1 and APPL2. Motriz, Revista de Educação Física. 
- Submetidos:

$\bigcirc$ Uphill running excessive training increases gastrocnemius glycogen content without significant changes of Akt, AMPKalpha, PGC-1alpha, GLUT-4 and GLUT-1 in C57BL/6 mice. 


\section{REFERÊNCIAS}

ABBOTT, B. C.; BIGLAND, B. The physiological cost of negative work. Journal of Physiology-London, v. 117, n. 3, p. P17-P17, 1952.

ARMSTRONG, L. E.; VANHEEST, J. L. The unknown mechanism of the overtraining syndrome - Clues from depression and psychoneuroimmunology. Sports Medicine, v. 32, n. 3, p. 185-209, 2002.

AVNI, D.; BIBERMAN, Y.; MEYUHAS, O. The 5' terminal oligopyrimidine tract confers translational control on TOP mRNAs in a cell type-and sequence context-dependent manner. Nucleic acids research, v. 25, n. 5, p. 995-1001, 1997.

BAIRD, M. F. et al. Creatine-kinase-and exercise-related muscle damage implications for muscle performance and recovery. Journal of nutrition and metabolism, v. 2012, 2012.

BENITO, B. et al. Cardiac arrhythmogenic remodeling in a rat model of long-term intensive exercise training. Circulation, p. CIRCULATIONAHA. 110.938282, 2010.

BERENJI, K. et al. Does load-induced ventricular hypertrophy progress to systolic heart failure? American Journal of Physiology-Heart and Circulatory Physiology, v. 289, n. 1, p. H8-H16, 2005.

BERNARDO, B. C. et al. Molecular distinction between physiological and pathological cardiac hypertrophy: experimental findings and therapeutic strategies. Pharmacology \& therapeutics, v. 128, n. 1, p. 191-227, 2010..

BODINE, S. C. mTOR signaling and the molecular adaptation to resistance exercise. Medicine and Science in Sports and Exercise, v. 38, n. 11, p. 1950-1957, 2006.

BOLUYT, M. O. et al. Alterations in cardiac gene expression during the transition from stable hypertrophy to heart failure. Marked upregulation of genes encoding extracellular matrix components. Circulation Research, v. 75, n. 1, p. 23-32, 1994.

BRADFORD, M. M. Rapid and sensitive method for quantitation of microgram quantities of protein utilizing principle of protein-dye binding. Analytical Biochemistry, v. 72, n. 1-2, p. 248-254, 19761976.

BREUCKMANN, F. et al. Myocardial Late Gadolinium Enhancement: Prevalence, Pattern, and Prognostic Relevance in Marathon Runners 1. Radiology, v. 251, n. 1, p. 50-57, 2009. 
COSTILL, D. L. et al. Effects of repeated days of intensified training on muscle glycogen and swimming performance. Medicine and Science in Sports and Exercise, v. 20, n. 3, p. 249254, Jun 1988.

DA ROCHA, A. L. et al. Downhill Running-Based Overtraining Protocol Improves Hepatic Insulin Signaling Pathway without Concomitant Decrease of Inflammatory Proteins. PLoS One, v. 10, n. 10, p. e0140020, 2015.

DA ROCHA, A. L. et al. Downhill running excessive training inhibits hypertrophy in mice skeletal muscles with different fiber type composition. Journal of cellular physiology, v. 231, n. 5, p. 1045-1056, 2016. ISSN 1097-4652.

DAVIS, J. M. et al. Curcumin effects on inflammation and performance recovery following eccentric exercise-induced muscle damage. American Journal of Physiology-Regulatory, Integrative and Comparative Physiology, v. 292, n. 6, p. R2168-R2173, 2007.

DEL AGUILA, L. F.; CLAFFEY, K. P.; KIRWAN, J. P. TNF- $\alpha$ impairs insulin signaling and insulin stimulation of glucose uptake in $\mathrm{C} 2 \mathrm{C} 12$ muscle cells. American Journal of PhysiologyEndocrinology And Metabolism, v. 276, n. 5, p. E849-E855, 1999.

DEL AGUILA, L. F. et al. Muscle damage impairs insulin stimulation of IRS-1, PI 3-kinase, and Akt-kinase in human skeletal muscle. American Journal of Physiology-Endocrinology and Metabolism, v. 279, n. 1, p. E206-E212, 2000.

ENOKA, R. M. Eccentric contractions require unique activation strategies by the nervous system. Journal of Applied Physiology, v. 81, n. 6, p. 2339-2346, 1996.

ESTIGOY, C. B. et al. Intercalated discs: multiple proteins perform multiple functions in nonfailing and failing human hearts. Biophysical Reviews, v. 1, n. 1, p. 43-49, 2009.

FAGARD, R. H.; UNIT, C. R.; LEUVEN, K. U. Impact of different sports and training on cardiac structure and function. Cardiology clinics, v. 15, n. 3, p. 397-412, 1997.

FERGUSON, S. et al. Cardiac performance in endurance-trained and moderately active young women. Medicine and science in sports and exercise, v. 33, n. 7, p. 1114-1119, 2001.

FERREIRA, J. C. B. et al. Maximal lactate steady state in running mice: Effect of exercise training. Clinical and Experimental Pharmacology and Physiology, v. 34, n. 8, p. 760-765, 2007.

FOSTER, C., AND M. LEHMAN et al. Overtraining syndrome 
p38? activity is required for maintenance of slow skeletal muscle size. Running Injuries, v. 45, n. 2, p. pp. 173-188, 1997.

FRANTZ, S. et al. Toll4 (TLR4) expression in cardiac myocytes in normal and failing myocardium. The Journal of clinical investigation, v. 104, n. 3, p. 271-280, 1999.

FRY, R. W.; MORTON, A. R.; KEAST, D. Overtraining in athletes - an update. Sports Medicine, v. 12, n. 1, p. 32-65, 1991.

GOTO, T. et al. Circulating concentrations of cardiac proteins indicate the severity of congestive heart failure. Heart, v. 89, n. 11, p. 1303-1307, 2003.

GROSSMAN, W.; JONES, D.; MCLAURIN, L. Wall stress and patterns of hypertrophy in the human left ventricle. Journal of Clinical Investigation, v. 56, n. 1, p. 56, 1975.

GUASCH, E. et al. Atrial fibrillation promotion by endurance exercise: demonstration and mechanistic exploration in an animal model. Journal of the American College of Cardiology, v. 62, n. 1, p. 68-77, 2013.

GUASCH, E.; NATTEL, S. CrossTalk proposal: Prolonged intense exercise training does lead to myocardial damage. The Journal of physiology, v. 591, n. 20, p. 4939-4941, 2013.

GUNASINGHE, S.; SPINALE, F. Myocardial basis for heart failure. Role of the Cardiac InterstitiumHeart Failure, p. 57-70, 2004.

HALSON, S. L.; JEUKENDRUP, A. E. Does overtraining exist? An analysis of overreaching and overtraining research. Sports Medicine, v. 34, n. 14, p. 967-981, 2004.

HAY, N.; SONENBERG, N. Upstream and downstream of mTOR. Genes \& development, v. 18, n. 16, p. 1926-1945, 2004..

HERSKOWITZ, A. et al. Cytokine mRNA expression in postischemic/reperfused myocardium. The American journal of pathology, v. 146, n. 2, p. 419, 1995.

HITTEL, D. S. et al. Myostatin Decreases with Aerobic Exercise and Associates with Insulin Resistance. Medicine and Science in Sports and Exercise, v. 42, n. 11, p. 2023-2029, 2010.

HOHL, R. et al. Development and Characterization of an Useful Animal Model of Overtraining. Medicine and Science in Sports and Exercise, v. 40, n. 5, p. S398-S398, 2008. 
HUONKER, M.; HALLE, M.; KEUL, J. Structural and functional adaptations of the cardiovascular system by training. International journal of sports medicine, v. 17, n. S 3, p. S164-S172, 1996.

IZUMO, S. et al. Myosin heavy chain messenger RNA and protein isoform transitions during cardiac hypertrophy. Interaction between hemodynamic and thyroid hormone-induced signals. Journal of Clinical Investigation, v. 79, n. 3, p. 970, 1987.

JORGENSEN, S. B. et al. Deletion of skeletal muscle SOCS3 prevents insulin resistance in obesity. Diabetes, v. 62, n. 1, p. 56-64, 2013.

JUNIOR, C. R. B. et al. Combined effect of AMPK/PPAR agonists and exercise training in mdx mice functional performance. PloS one, v. 7, n. 9, p. e45699, 2012.

KEIZER, H. A. Neuroendocrine aspects of overtraining. In: R. B. KREIDER, A. C. F. A. M. L. O. T. (Ed.). Overtraining in Sport. Champaign, IL: Human Kinetics, p. 145-168, 1998.

KEMI, O. J. et al. Phosphorylation of regulatory proteins CaMK, PLN and AKT precedes cardiomyocyte adaptation to exercise training. Journal of Molecular and Cellular Cardiology, v. 40, n. 6, p. 1006, 2006.

KEMI, O. J. et al. Activation or inactivation of cardiac Akt/mTOR signaling diverges physiological from pathological hypertrophy. Journal of cellular physiology, v. 214, n. 2, p. 316-321, 2008.

KEMI, O. J. et al. Moderate vs. high exercise intensity: differential effects on aerobic fitness, cardiomyocyte contractility, and endothelial function. Cardiovascular research, v. 67, n. 1, p. 161-172, 2005.

KEMI, O. J. et al.. Aerobic fitness is associated with cardiomyocyte contractile capacity and endothelial function in exercise training and detraining. Circulation, v. 109, n. 23, p. 28972904, 2004.

KENTTÄ, G.; HASSMÉN, P.; RAGLIN, J. Overtraining and staleness in Swedish age-group athletes: association with training behavior and psychosocial stressors. Int J Sports Med, v. 22, p. 460-5, 2001.

KRAEMER, W. J.; RATAMESS, N. A. Fundamentals of resistance training: progression and exercise prescription. Medicine and science in sports and exercise, v. 36, n. 4, p. 674-688, 2004. 
KREIDER, R.B. et al. Overtraining in sport: terms, definitions, and prevalence. In: PEDERSEN, B. K. (Ed.). Exercise Immunology. Champaign: Human Kinetics, 1998. p.78pp. 75-88.

LA GERCHE, A. et al. Disproportionate exercise load and remodeling of the athlete's right ventricle. Med Sci Sports Exerc, v. 43, n. 6, p. 974-981, 2011.

LAEMMLI, U. K. Cleavage of structural proteins during assembly of head of bacteriophaget4. Nature, v. 227, n. 5259, p. 680, 1970.

LEHMANN, M. et al. Autonomic imbalance hypothesis and overtraining syndrome. Medicine and Science in Sports and Exercise, v. 30, n. 7, p. 1140-1145, 1998.

LI, H. L. et al. Long-term activation of adenosine monophosphate-activated protein kinase attenuates pressure-overload-induced cardiac hypertrophy. Journal of cellular biochemistry, v. 100, n. 5, p. 1086-1099, 2007.

LINDSAY, M. M.; DUNN, F. G. Biochemical evidence of myocardial fibrosis in veteran endurance athletes. British journal of sports medicine, v. 41, n. 7, p. 447-452, 2007.

LINDSTEDT, S. L.; LASTAYO, P. C.; REICH, T. E. When active muscles lengthen: Properties and consequences of eccentric contractions. News in Physiological Sciences, v. 16, p. 256$261,2001$.

MA, X. et al. Cardiac fibrosis alleviated by exercise training is AMPK-dependent. PloS one, v. 10, n. 6, p. e0129971, 2015.

MCMULLEN, J. R. et al. Phosphoinositide 3-kinase (p110 $\alpha$ ) plays a critical role for the induction of physiological, but not pathological, cardiac hypertrophy. Proceedings of the National Academy of Sciences, v. 100, n. 21, p. 12355-12360, 2003.

MEDZHITOV, R.; JANEWAY, C. A. Innate immunity: the virtues of a nonclonal system of recognition. cell, v. 91, n. 3, p. 295-298, 1997.

MEEUSEN, R. et al. Prevention, diagnosis and treatment of the overtraining syndrome: Joint consensus statement of the European College of Sport Science (ECSS) and the American College of Sports Medicine (ACSM). European Journal of Sport Science, v. 13, n. 1, p. 124, 2013.

MEEUSEN, R. et al. Prevention, diagnosis and treatment of the Overtraining Syndrome - ECSS Position Statement 'Task Force'. European Journal of Sport Science, v. 6, n. 1, p. 1-14, 2006. 
MOLKENTIN, J. D.; DORN II, G. W. Cytoplasmic signaling pathways that regulate cardiac hypertrophy. Annual review of physiology, v. 63, n. 1, p. 391-426, 2001.

MORGAN, W. P. et al. Personality structure, mood states, and performance in elite male distance runners. International Journal of Sport Psychology, 1988.

MORKIN, E. Control of cardiac myosin heavy chain gene expression. Microscopy research and technique, v. 50, n. 6, p. 522-531, 2000.

NEWSHOLME, E. et al. A biochemical mechanism to explain some characteristics of overtraining. 1991.

OGASAWARA, R. et al. The order of concurrent endurance and resistance exercise modifies mTOR signaling and protein synthesis in rat skeletal muscle. American Journal of Physiology-Endocrinology and Metabolism, v. 306, n. 10, p. E1155-E1162, 2014.

PAULI, J. R. et al. Acute physical exercise reverses S-nitrosation of the insulin receptor, insulin receptor substrate 1 and protein kinase B/Akt in diet-induced obese Wistar rats. Journal of Physiology-London, v. 586, n. 2, p. 659-671, 2008.

PEREIRA, B. C. et al. Eccentric exercise leads to glial activation but not apoptosis in mice spinal cords. International journal of sports medicine, v. 36, n. 05, p. 378-385, $2015 \mathrm{a}$.

PEREIRA, B. C. et al Nonfunctional overreaching leads to inflammation and myostatin upregulation in swiss mice. International journal of sports medicine, v. 35, n. 02, p. 139146, 2014a.

PEREIRA, B. C. et al. Excessive eccentric exercise leads to transitory hypothalamic inflammation, which may contribute to the low body weight gain and food intake in overtrained mice. Neuroscience, v. 311, p. 231-42, 2015b.

PEREIRA, B. C. et al. Excessive eccentric exercise-induced overtraining model leads to endoplasmic reticulum stress in mice skeletal muscles. Life sciences, v. 145, p. 144-151, 2016.

PEREIRA, B. C. et al. A new overtraining protocol for mice based on downhill running sessions. Clin Exp Pharmacol Physiol, v. 39, n. 9, p. 793-8, 2012

PEREIRA, B. C. et al. Overtraining is associated with DNA damage in blood and skeletal muscle cells of Swiss mice. BMC physiology, v. 13, n. 1, p. 11, 2013.

PEREIRA, B. C. et al. Eccentric exercise leads to performance decrease and insulin signaling impairment. Med Sci Sports Exerc, v. 46, n. 4, p. 686-94, 2014 b. 
PLUIM, B. M. et al. The athlete's heart a meta-analysis of cardiac structure and function.

Circulation, v. 101, n. 3, p. 336-344, 2000.

RAGLIN, J. Overtraining and staleness-Psychometric monitoring of endurance athletes. Handbook of research on sports psychology, 1993.

RICHARDSON, R. S. Oxygen transport: air to muscle cell. Medicine and science in sports and exercise, v. 30, n. 1, p. 53-59, 1998.

ROBSON, P. J. Elucidating the unexplained underperformance syndrome in endurance athletes - The interleukin-6 hypothesis. Sports Medicine, v. 33, n. 10, p. 771-781, 2003.

ROPELLE, E. R. et al. Targeted Disruption of Inducible Nitric Oxide Synthase Protects Against Aging, S-Nitrosation, and Insulin Resistance in Muscle of Male Mice. Diabetes, v. 62, n. 2, p. 466-470, 2013.

S, H. et al. Effects of eccentrically and concentrically biased training on mouse muscle phenotype. Medicine and Science in Sports and Exercise, v. 45, n. 8, 2013.

SCHNOHR, P.; GRANDE, P.; CHRISTIANSEN, C. Enzyme activities in serum after extensive exercise, with special reference to creatine kinase MB. Acta Medica Scandinavica, v. 208, n. 1-6, p. 229-231, 1980.

SMITH, L. L. Cytokine hypothesis of overtraining: a physiological adaptation to excessive stress? Medicine and Science in Sports and Exercise, v. 32, n. 2, p. 317-331, 2000.

SOCIETY, T. A. P. Resource book for the design of animal exercise protocols, 2006.

SONG, X. et al. mTOR attenuates the inflammatory response in cardiomyocytes and prevents cardiac dysfunction in pathological hypertrophy. American Journal of Physiology-Cell Physiology, v. 299, n. 6, p. C1256-C1266, 2010.

STEENSBERG, A. et al. IL-6 and TNF- $\alpha$ expression in, and release from, contracting human skeletal muscle. American Journal of Physiology-Endocrinology and Metabolism, v. 283, n. 6, p. E1272-E1278, 2002.

STEINACKER, J. M. et al. Thyroid hormones, cytokines, physical training and metabolic control. Hormone and Metabolic Research, v. 37, n. 9, p. 538-544, 2005.

TOTSUKA, M. et al. Break point of serum creatine kinase release after endurance exercise. Journal of Applied Physiology, v. 93, n. 4, p. 1280-1286, 2002. 
WALSH, K. Akt signaling and growth of the heart. Circulation, v. 113, n. 17, p. 2032-2034, 2006.

WILHELM, M. et al. Atrial remodeling, autonomic tone, and lifetime training hours in nonelite athletes. The American journal of cardiology, v. 108, n. 4, p. 580-585, 2011.

WISLØFF, U. et al. Aerobic exercise reduces cardiomyocyte hypertrophy and increases contractility, Ca2+ sensitivity and SERCA-2 in rat after myocardial infarction. Cardiovascular research, v. 54, n. 1, p. 162-174, 2002.

WISLØFF, U. et al.. Increased contractility and calcium sensitivity in cardiac myocytes isolated from endurance trained rats. Cardiovascular research, v. 50, n. 3, p. 495-508, 2001. 